\title{
Equations for the Radiofrequency Magnetic Permeameter
}

\author{
Cletus A. Hoer and Alvin L. Rasmussen
}

(October 25, 1962)

\begin{abstract}
The rf permeameter is an impedance transformer for measuring toroidal-shaped magnetic materials at radiofrequencies. Several equations already exist for calculating permeability $\left(\mu^{\prime}\right)$ and dissipation factor $(\tan \delta$ ) from measured input impedances of the permeameter. The results from these equations do not agree with each other except over a small range of $\tan \delta$. In this paper the permeameter is represented by its equivalent T-network and an exact solution for $\mu^{\prime}$ and $\tan \delta$ is obtained in terms of the input impedances and the impedance of a calibration core. The resulting equations are valid for all values of $\mu^{\prime}$ and $\tan \delta$ for the conditions discussed in the paper. Values of $\mu^{\prime}$ and $\tan \delta$ calculated from these exact equations are compared with those calculated from previous equations, and these results, differing as much as several orders of magnitude, are shown graphically. A frequency range from 0.1 to $50 \mathrm{Mc} / \mathrm{s}$ and a tan $\delta$ range from 0.0005 to 5 are covered.
\end{abstract}

\section{Introduction}

Since the development of the radiofrequency permeameter ${ }^{1}[1,2,3,4]^{2}$ several equations have been derived for calculating the permeability $\left(\mu^{\prime}\right)$ and dissipation factor $\left(\tan \delta=\frac{\mu^{\prime \prime}}{\mu^{\prime}}\right.$ where $\mu^{\prime}$ and $\mu^{\prime \prime}$ are related by the complex permeability, $\mu^{*}=\mu^{\prime}-j \mu^{\prime \prime}$ ) of toroidal-shaped magnetic materials. In all of these derivations various assumptions have been made about the transformer characteristics of the permeameter. Although useful in the design and application of the rf permeameter, these assumptions have led to a number of expressions each of which gives correct values of $\mu^{\prime}$ and $\tan \delta$ for only a limited range of $\tan \delta$. The equations here derived are valid for all values of $\mu^{\prime}$ and $\tan \delta$ for the conditions discussed in section 2. Problems arising from assuming certain characteristics of the transformer are circumvented by analyzing the equivalent $T$-network corresponding to the permeameter. It is assumed that the arms of the equivalent network are not a function of the load impedance. A low loss toroidalshaped magnetic material is used as an impedance standard in evaluating the T-network. The T-network yields a set of exact equations which have been used in determining values of $\mu^{\prime}$ and $\tan \delta$ for tan $\delta$ ranging from very low loss $(0.0005)$ to very high loss (5.0). These values agree within experimental error with those obtained by other methods not using a permeameter. An evaluation of all permeameter formulas shows that the former equations for $\tan \delta$ are in error as much as several orders of magnitude for low loss materials, and that one of these equations for $\mu^{\prime}$ is in error as much as an order of magnitude for high loss materials.

The use of the permeameter makes the measurement of many magnetic materials possible in the frequency range of 0.1 to $50 \mathrm{Mc} / \mathrm{s}$. These results are not readily obtained using other techniques.

\footnotetext{
1 See appendix A for a description of the rf permeameter.
}

2 Figures in brackets indicate the literature references at the end of this paper.

\section{Derivation of the Exact Equation}

A brief derivation of the permeameter equations for $\mu^{\prime}$ and $\tan \delta$ is given in eqs (1) through (11). The rf permeameter is an impedance transformer and can be represented by the $T$-network shown in figure 1 .

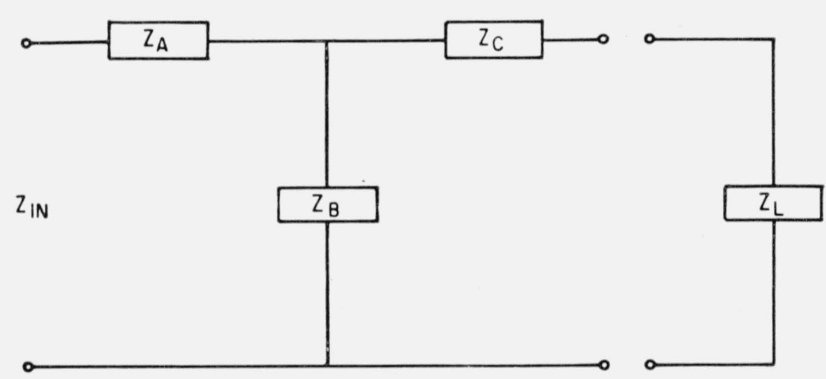

Figure 1. Equivalent T-network for rf permeameter.

The input impedance is $Z_{\mathrm{in}}=Z_{A}+\frac{Z_{B}\left(Z_{C}+Z_{L}\right)}{Z_{B}+Z_{C}+Z_{L}}$, where $Z_{A}, Z_{B}$, and $Z_{C}$ are the impedances ${ }^{3}$ of the arms of the T-network, and $Z_{L}$ is the impedance added to the secondary. If the input impedance is measured with three different known values of $Z_{L}$, an equation for any unknown $Z_{L}$ may be derived eliminating $Z_{A}, Z_{B}$, and $Z_{C}$, the source of error in previous derivations. Let the input impedance be measured using the following definitions:

$Z_{1}=Z_{\text {in }}$ when the secondary is open; $Z_{L}=\infty$.

$Z_{0}=Z_{\text {in }}$ when the secondary is closed without a sample enclosed; $Z_{L}=0$ (this corresponds to the output terminals being shorted in fig. 1).

$Z_{f^{\prime}}=Z_{\text {in }}$ when the secondary is closed with a known or standard impedance sample enclosed; $Z_{L}$ $=Z_{S}$, where $Z_{S}$ is the impedance of the standard sample minus the reactance of the space it replaces.

${ }_{3}$ The impedance due to the shorting plate is included in $Z_{c}$. 
$Z_{f}=Z_{\text {in }}$ when the secondary is closed with an unknown sample enclosed; $Z_{L}=Z_{u}$, where $Z_{u}$ is the impedance of the unknown sample minus the reactance of the space it replaces.

When a sample is enclosed in the secondary to measure $Z_{f}$ or $Z_{f^{\prime}}$, it is assumed that there is negligible direct coupling with the primary and that there is no significant change in the distributed capacitance of the secondary. If there is no measurable change in $Z_{1}$ when a sample is placed in the open secondary, then the coupling and change in distributed capacitance are negligible.

Expressing the input impedance in terms of $Z_{A}$, $Z_{B}, Z_{C}$, and $Z_{L}$ gives

$$
\begin{aligned}
& Z_{1}=R_{1}+j \omega L_{1}=Z_{A}+Z_{B}, \\
& Z_{0}=R_{0}+j \omega L_{0}=Z_{A}+\frac{Z_{B} Z_{C}}{Z_{B}+Z_{C}}, \\
& Z_{f^{\prime}}=R_{f^{\prime}}+j \omega L_{f^{\prime}}=Z_{A}+\frac{Z_{B}\left(Z_{C}+Z_{S}\right)}{Z_{B}+Z_{C}+Z_{S}}, \\
& Z_{f}=R_{f}+j \omega L_{f}=Z_{A}+\frac{Z_{B}\left(Z_{C}+Z_{u}\right)}{Z_{B}+Z_{C}+Z_{u}}
\end{aligned}
$$

From these equations the unknown impedance, $Z_{u}$, may be written

$$
Z_{u}=Z_{S}\left(\frac{Z_{f^{\prime}}-Z_{1}}{Z_{f^{\prime}}-Z_{0}}\right)\left(\frac{Z_{f}-Z_{0}}{Z_{f}-Z_{1}}\right)
$$

The product of the first two factors on the right is a constant for a permeameter at a given frequency. Defining this complex calibration constant as $\omega(x+j y)$ we have

$$
\omega(x+j y)=Z_{S}\left(\frac{Z_{f^{\prime}}-Z_{1}}{Z_{f^{\prime}}-Z_{0}}\right)
$$

By substituting (6) into (5) and expressing $Z_{u}$ in terms of $\mu^{\prime}$ and $\tan \delta$, (5) becomes

$$
\omega L_{a}\left[\mu^{\prime} \tan \delta+j\left(\mu^{\prime}-1\right)\right]=\omega(x+j y)\left(\frac{Z_{f}-Z_{0}}{Z_{f}-Z_{1}}\right)
$$

where $L_{a}=$ equivalent air inductance of the sample. ${ }^{4}$ Solving (7) for $\mu^{\prime}$ and $\tan \delta$ gives ${ }^{5}$

$$
\begin{aligned}
\mu^{\prime}-1 & =\frac{(x / y) B+A}{\left(R_{f 1}\right)^{2}+\left(\omega L_{f 1}\right)^{2}}\left(\frac{y}{L_{a}}\right) \\
\tan \delta & =\frac{(x / y) A-B}{(x / y) B+A}\left(\frac{\mu^{\prime}-1}{\mu^{\prime}}\right)
\end{aligned}
$$

${ }^{4} L_{a}=2 \times$ (height in meters) $\times \ln$ (outside diameter/inside diameter) $\times 10^{-7}$ henrys. $-L_{1}$. where

$$
\begin{aligned}
& A=R_{f 0} R_{f 1}+\omega^{2} L_{f 1} L_{f 0} \\
& B=\omega L_{f 0} R_{f 1}-\omega L_{f 1} R_{f 0} .
\end{aligned}
$$

The calibration constants $x$ and $y$ may be expressed in terms of $\mu^{\prime}$ and $\tan \delta$ of the standard core. $Z_{S}$ may be written

$$
Z_{S}=\omega L_{a s}\left[\mu_{s}^{\prime} \tan \delta_{s}+j\left(\mu_{s}^{\prime}-1\right)\right] .
$$

Then from (6) we have

where

$$
\begin{gathered}
y=\frac{L_{a s}\left[E\left(\mu_{s}^{\prime}-1\right)-F \mu_{s}^{\prime} \tan \delta_{s}\right]}{\left(R_{f^{\prime} 0}\right)^{2}+\left(\omega L_{f^{\prime} 0}\right)^{2}} \\
\frac{x}{y}=\frac{F\left(\mu_{s}^{\prime}-1\right)+E \mu_{s}^{\prime} \tan \delta_{s},}{E\left(\mu_{s}^{\prime}-1\right)-F \mu_{s}^{\prime} \tan \delta_{s}},
\end{gathered}
$$

$$
\begin{aligned}
& E=R_{f^{\prime} 0} R_{f^{\prime} 1}+\omega^{2} L_{f^{\prime} 1} L_{f^{\prime} 0} \\
& F=\omega L_{f^{\prime} 0} R_{f^{\prime} 1}-\omega L_{f^{\prime} 1} R_{f^{\prime} 0} .
\end{aligned}
$$

Primed subscripts and quantities with subscript $s$ refer to the standard of known impedance.

Assuming that the load impedance does not change the characteristics of the T-network, these equations should be exact for all values of $\mu^{\prime}$ and $\tan \delta$. 'The accuracy of the resulting answers appears to be limited only by the accuracy of the device used to measure the input impedances, the reproducibility of the secondary "short," and the accuracy of the standard impedance $Z_{S}$. Reducing errors due to the impedance measuring device has been discussed in the literature $[1,3]$.

The present secondary shorting arrangement is silver-to-silver surface contact formed under high and relatively evenly distributed pressure exerted by a cap which is screwed onto the permeameter (fig. 2). This arrangement yields a contact resistance

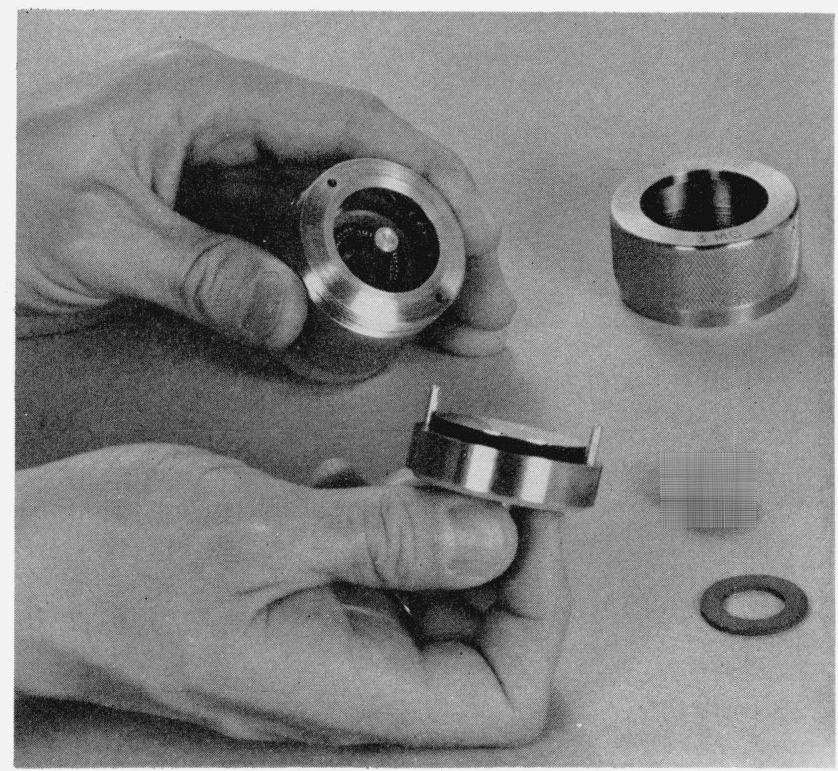

FIGURE 2. An rf permeameter showing silver to silver contact surfaces. 
which is reproducible to a precision approximately equal to or greater than that of the impedance measuring devices presently used. The error introduced by calibrating the permeameter with a known impedance may be minimized by choosing the proper calibration core.

\section{Approximate Equations for Low Loss Samples}

The working eqs (8) through (11) can be simplified considerably for low loss samples. These approximate equations are also useful in determining the desired characteristics of a standard calibration core. Equations (8) through (11) may be expressed in terms of resonating capacitance and $Q$ by letting

$Q_{1}=\omega L_{1} / R_{1} \quad Q_{0}=\omega L_{0} / R_{0} \quad Q_{f}=\omega L_{f} / R_{f} \quad Q_{f^{\prime}}=\omega L_{f^{\prime}} / R_{f}$ $C_{1}=1 / \omega^{2} L_{1} \quad C_{0}=1 / \omega^{2} L_{0} \quad C_{f}=1 / \omega^{2} L_{f} \quad C_{f^{\prime}}=1 / \omega^{2} L_{f^{\prime}}$.

If the assumption is made that the square of each $Q$ is much greater than one, that is

$$
Q_{1}^{2} \gg 1 \quad Q_{0}^{2} \gg 1 \quad Q_{f}^{2} \gg 1 \quad Q Q_{f^{\prime}}^{2} \quad \gg 1,
$$

and that $\tan \delta \ll 1$, then (8) and (9) reduce to

$$
\begin{aligned}
& \mu^{\prime}-1=\frac{y}{L_{a}} \frac{L_{f 0}}{L_{f 1}}=\frac{y}{L_{a}} \frac{C_{1}}{C_{0}} \frac{C_{0 f}}{C_{1 f}} \\
& \tan \delta=\left(\frac{x}{y}-\frac{B}{A}\right)\left(\frac{\mu^{\prime}-1}{\mu^{\prime}}\right)
\end{aligned}
$$

where $B / A$ reduces to

$$
\frac{B}{A}=\frac{R_{f 1}}{\omega L_{f 1}}-\frac{R_{f 0}}{\omega L_{f 0}}=\frac{C_{f}}{C_{0 f} C_{f 1}}\left\{\frac{C_{0 f}}{Q_{1}}+\frac{C_{f 1}}{Q_{0}}-\frac{C_{01}}{Q_{f}}\right\} .
$$

Also (10) and (11) reduce to

$$
\begin{aligned}
& y=\left(\mu_{s}^{\prime}-1\right) L_{a s} \frac{L_{f^{\prime} 1}}{L_{f^{\prime} 0}}=\left(\mu_{s}^{\prime}-1\right) L_{a s} \frac{C_{0}}{C_{1}} \frac{C_{1 f^{\prime}}}{C_{0 f^{\prime}}} \\
& \frac{x}{y}=\frac{\mu_{s}^{\prime}}{\mu_{s}^{\prime}-1} \tan \delta_{s}+\frac{F}{E}
\end{aligned}
$$

where $F / E$ reduces to

$$
\frac{F}{E}=\frac{R_{f^{\prime} 1}}{\omega L_{f^{\prime} 1}}-\frac{R_{f^{\prime} 0}}{\omega L_{f^{\prime} 0}}=\frac{C_{f^{\prime}}}{C_{0 f^{\prime}} C_{f^{\prime} 1}}\left\{\frac{C_{0 f^{\prime}}}{Q_{1}}+\frac{C_{f^{\prime} 1}}{Q_{0}}-\frac{C_{01}}{Q_{f^{\prime}}}\right\} .
$$

The results from (8a) through (11a) agree with the results from (8) through (11) to better than 1 percent for the NBS permeameters, provided that $\tan \delta<0.1$. In part 4 it is suggested that the calibration core have a low loss. The calibration constants $x$ and $y$ may then be calculated from (10a) and (11a).

\section{Reference Sample or Calibration Core}

The reference sample presently used at the $\mathrm{Na}$ tional Bureau of Standards to find the calibration constants $x$ and $y$ is a stable low loss powered iron carbonyl SF core. The most accurate determination of $y$ can be made if the calibration core is machined to have an $L_{a}$ such that either $L_{f^{\prime} 1} / L_{0 f^{\prime}}$ or $C_{f^{\prime} 1} / C_{0 f^{\prime}}$ in (10a) approaches unity, depending on whether inductance or capacitance measurements are being made. Since $y$ and $C_{0} / C_{1}$ do not change greatly over the frequency range of 0.1 to $50 \mathrm{Mc} / \mathrm{s}$, one calibration core mav be cut to have an $L_{a}$ that will be near optimum for calibration over this frequency range.

The most accurate determination of $x / y$ may be made by using a core with the lowest possible value of $\tan \delta_{s}$. The value of $x / y$ for the National Bureau of Standards permeameters is of the order of 0.01 . Examination of (11a) shows that if $\tan \delta_{S}$ is much less than 0.01 , say $0.0001, x / y$ is approximately independent of tan $\delta_{S}$ in which case $x / y \approx F / E$ and only an approximate value of $\tan \delta_{S}$ need be known. Therefore, the permeameter may be calibrated with a minimum of error by choosing a very low loss material having a permeability that is stable with time and temperature and having an optimum value of $L_{u}$

The permeability $\mu_{s}^{\prime}$ and loss tangent $\tan \delta_{s}$ of the SF calibration core were determined in the frequency range of 1.0 to $50 \mathrm{Mc} / \mathrm{s}$ as follows. The core was measured in demountable coils and coaxial lines below $1.0 \mathrm{Mc} / \mathrm{s}$ on a Maxwell-type bridge and in variable length re-entrant cavities above $50 \mathrm{Mc} / \mathrm{s}$. The $\mu_{s}^{\prime}$ remained constant from 0.1 to $100 \mathrm{Mc} / \mathrm{s}$. To obtain a curve of $\tan \delta_{S}$ between 1.0 and $50 \mathrm{Mc} / \mathrm{s}$ the curve above $50 \mathrm{Mc} / \mathrm{s}$ was extended down and the curve below $1 \mathrm{Mc} / \mathrm{s}$ was extended up to make a smooth transition as shown in figure 3 .

From (8a) and (10a) it can be shown that any error, $\Delta \mu_{s}^{\prime}$, in $\mu_{s}^{\prime}$ will produce an error, $\Delta \mu^{\prime}$, in the $\mu^{\prime}$ of any measured sample of an amount

$$
\Delta \mu^{\prime}=\Delta \mu_{s}^{\prime} \frac{\mu^{\prime}-1}{\mu_{s}^{\prime}-1}
$$

The percent error in $\mu^{\prime}$ is approximately equal to the percent error in $\mu_{s}^{\prime}$.

Likewise it can be shown from (9a) and (11a) that any error, $\Delta \tan \delta_{S}$, in $\tan \delta_{S}$ will produce an error, $\Delta \tan \delta$, in the $\tan \delta$ of any measured sample of an amount

$$
\Delta \tan \delta=\Delta \tan \delta_{s} \frac{\mu_{s}^{\prime}}{\mu_{s}^{\prime}-1} \frac{\mu^{\prime}-1}{\mu^{\prime}} \approx \Delta \tan \delta_{s} .
$$


Therefore if a more accurate determination of $\mu_{s}^{\prime}$ and $\tan \delta_{S}$ is made later, the $\mu^{\prime}$ and $\tan \delta$ of previously measured samples may easily be corrected using (12) and (13).

\section{Q-Meter Measurements}

Since the permeameter is often measured on a $Q$ meter, it is of value to note that most of the corrections to the measured $Q$ and $C$ due to residuals in the Q-meter cancel out when using (8a) through (11a). A $Q$-meter circuit including the residuals $R_{m}, L^{\prime}, L_{c}$, and $R_{v}$ is shown in figure 4 . The effective $Q, Q_{e}$, and

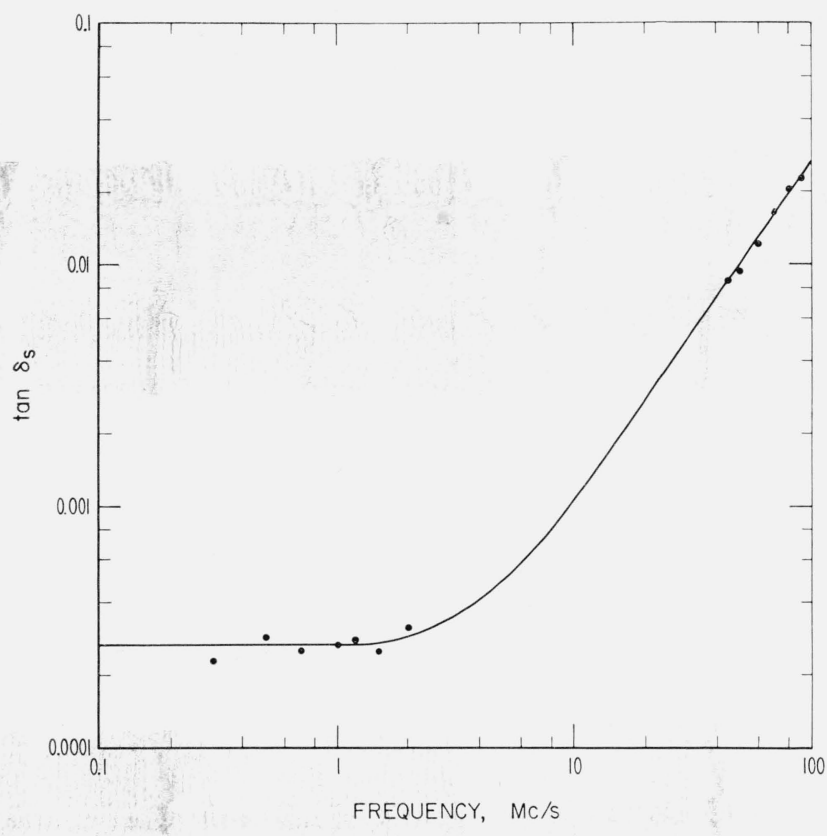

Figure 3. Carbonyl SF calibration core, tan $\delta_{s}$ versus frequency showing demountable coil results (0.1 to $2.0 \mathrm{Mc} / \mathrm{s})$ and re-entrant cavity results $(45$ to $100 \mathrm{Mc} / \mathrm{s})$.

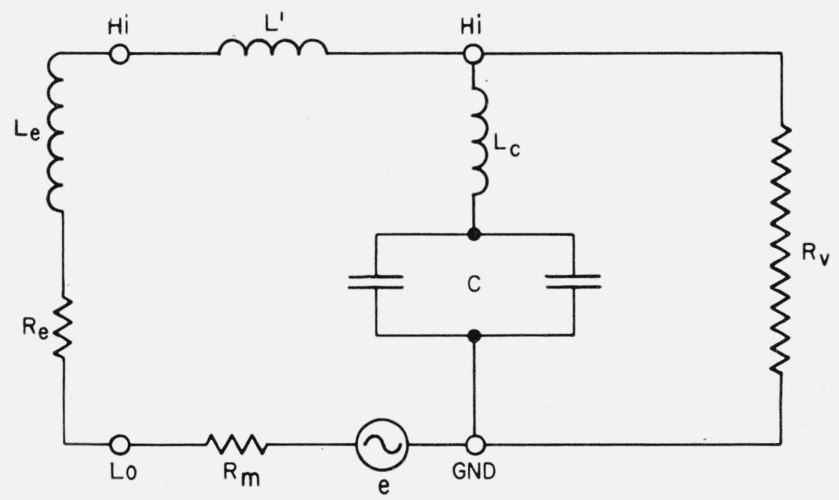

FIGURE 4. Q meter approximate equivalent measuring circuit. the effective capacitance, $C_{e}$, can be expressed in terms of the indicated $Q, Q_{i}$, and indicated capacitance, $C_{i}$, as

$$
\begin{gathered}
C_{e}=\frac{C_{i}}{1-\omega^{2} L_{m} C_{i}} \\
Q_{e}=\frac{Q_{i}\left(1-\omega^{2} L_{m} C_{i}\right)}{1-\omega C_{i} Q_{i}\left(R_{m}+R_{G}^{\prime}\right)-\omega^{2} L_{c} C_{i}}
\end{gathered}
$$

where$$
L_{m}=L^{\prime}+L_{c}
$$

and

$$
R_{G}^{\prime}=\frac{\left(\omega^{2} L_{c} C_{i}-1\right)^{2}}{\omega^{2} C_{i}^{2} R_{v}}
$$

In obtaining (14) and (15) it is assumed that

$$
R_{v}^{2} \gg\left(\frac{1-\omega^{2} L_{c} C_{i}}{\omega C_{i}}\right)^{2} .
$$

If each capacitance in (8a) and (10a) is replaced by the corresponding corrected expression from (14), the resulting equation for $\mu^{\prime}-1$ is identical to (8a) in which indicated values of capitance are used. The corrections cancel.

If each capacitance and $Q$ in (9a) and (11a) is replaced by the corresponding corrected expression from (14) and (15) the resulting expression for tan $\delta$ becomes

$$
\tan \delta=\left(\frac{x}{y}-\frac{B}{A}+K\right)\left(\frac{\mu^{\prime}-1}{\mu^{\prime}}\right)
$$

where $K$ is a correction term which becomes significant above about $10 \mathrm{Mc} / \mathrm{s}$.

$$
\begin{aligned}
K=\omega^{2} L_{c} & {\left[\frac{C_{f}}{C_{0 f} C_{f 1}}\left\{\frac{C_{1} C_{0 f}}{Q_{1}}+\frac{C_{0} C_{f 1}}{Q_{0}}-\frac{C_{f} C_{01}}{Q_{f}}\right\}\right.} \\
& \left.-\frac{C_{f^{\prime}}}{C_{0 \mathrm{f}^{\prime}} C_{f^{\prime} 1}}\left\{\frac{C_{1} C_{0 f^{\prime}}}{Q_{1}}+\frac{C_{0} C_{f^{\prime} 1}}{Q_{0}}-\frac{C_{f^{\prime}} C_{01}}{Q_{f^{\prime}}}\right\}\right] .
\end{aligned}
$$

Each $Q$ and capacitance in (16) and (17) is the indicated value as read on the $Q$-meter. Note that $L_{c}$ is the only residual appearing in the correction term. The corrections due to $L^{\prime}, R_{m}$, and $R_{v}$ cancel. Tan $\delta$ may be corrected either with (17) or by correcting each indicated $Q$ with the expression

$$
Q_{e}=\frac{Q_{i}}{1-\omega^{2} L_{c} C_{i}}
$$

and using these corrected values of $Q$ in (9a) and (11a).

\section{Comparison With Previous Permeameter Equations}

The following eqs. (18) through (24) have been used in the past to evaluate $\mu^{\prime}$ and $\tan \delta$ from permeameter data using the $Q$-meter.

From circuit (a) and assumptions 1, 2, and 3 (fig. 5) Haas [1] derived (18) and (19). 


$$
\mu^{\prime}-1=\frac{K}{L_{a}} \frac{C_{0 f}}{C_{f 1}}
$$

$\tan \delta=\frac{C_{01} C_{f 1}}{C_{0 f}}\left[\frac{1}{C_{f 1}^{2}}\left(\frac{C_{f}}{Q_{f}}-\frac{C_{f}^{2} C_{1}}{C_{1}^{2} Q_{1}}\right)-\frac{1}{C_{01}^{2}}\left(\frac{C_{0}}{Q_{0}}-\frac{C_{0}^{2} C_{1}}{C_{1}^{2} Q_{1}}\right)\right]$.

Because (19) becomes negative when measuring relatively low loss materials, McKnight [2] derived (20) using circuit (b) and assumptions 1, 2, and 3

$\tan \delta=\frac{C_{01} C_{f 1}}{C_{0 f}}\left[\frac{1}{C_{f 1}^{2}}\left(\frac{C_{f}}{Q_{f}}-\frac{C_{1}}{Q_{1}}\right)-\frac{1}{C_{01}^{2}}\left(\frac{C_{0}}{Q_{0}}-\frac{C_{1}}{Q_{1}}\right)\right]$.

Equation (20a) reduces to (19) plus $2 / Q_{1}$

$$
\tan \delta=\tan \delta_{(19)}+2 / Q_{1} .
$$

In another attempt to correct the error of (19), Rasmussen, Enfield, and Hess [3] derived eq (21) from circuit (c) and assumptions 1, 2, 3, 4, and 5 . In the primary section the losses of the winding were separated from those of the material. Tan $\delta$ is here defined as $\mu^{\prime \prime} / \mu^{\prime}$, not as $\mu^{\prime \prime} /\left(\mu^{\prime}-1\right)$ as was done in [1] and [2].

$$
\tan \delta=\left(\tan \delta_{(19)}+2 \frac{R_{P}}{X_{P}}\right) \frac{\mu^{\prime}-1}{\mu^{\prime}} .
$$

${ }^{6}$ Subscripts on $\tan \delta$ refer to equations giving the associated expression for $\tan \delta$.

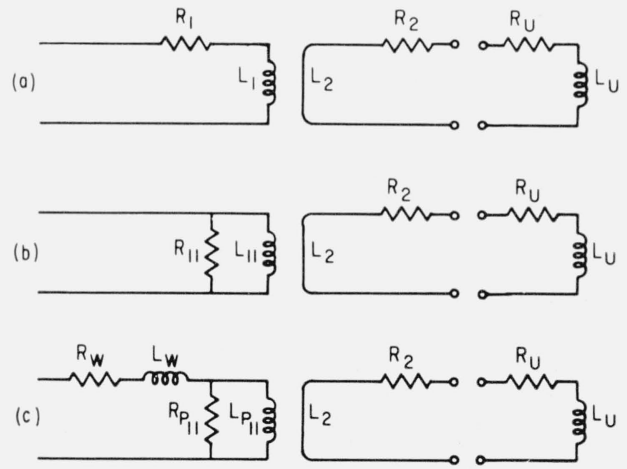

$$
\begin{array}{ll}
\text { ASSUMPTIONS } \\
\text { 1. } & R_{1}^{2} \ll<\omega^{2} L_{1}^{2} \\
\text { 2. } & R_{2}^{2} \ll \omega^{2} L_{2}^{2} \\
\text { 3. } & \left(R_{2}+R_{U}\right)^{2}<<\omega^{2}\left(L_{2}+L_{U}\right)^{2} \\
\text { 4. } & \left(R_{p} / X_{p}\right)^{2} \ll 1 \\
\text { 5. } & 2\left(R_{p} / X_{P}\right) \operatorname{TAN} \delta_{(19)} \ll 1 \\
\text { 6. } & 2\left(R_{p} / X_{P}\right) \operatorname{TAN} \delta_{(24)} \ll 1
\end{array}
$$

FIgURE 5. Circuits used and assumptions made in deriving equations (18) through (24).

$R_{p}$ and $X_{p}$ are the series resistance and reactance of the primary material.
Since assumption 3 is not valid when measuring relatively high loss samples, Rasmussen and Hess [4] derived (22) through (25), using circuit (c) and assumptions 1, 2, 4, and 6 .

$$
\begin{gathered}
\mu^{\prime}-1=\frac{K^{\prime}}{L_{a}} \frac{C_{0}}{C_{1}}(D-1) \\
\tan \delta=\left(\tan \delta_{(24)}+2 \frac{R_{P}}{X_{P}}\right)^{\mu^{\prime}-1} \mu^{\prime}
\end{gathered}
$$

where

$$
\tan \delta_{(24)}=\frac{\frac{1}{C_{f 1}}\left(\frac{C_{1}}{Q_{f}}-\frac{C_{f}}{Q_{1}}\right) D-\frac{1}{C_{01}}\left(\frac{C_{1}}{Q_{0}}-\frac{C_{0}}{Q_{1}}\right)}{D-1}
$$

and

$$
D=\frac{\frac{C_{01}}{C_{0}} C_{f} C_{f 1}}{C_{f 1}{ }^{2}+\left(\frac{C_{1}}{Q_{f}}-\frac{C_{f}}{Q_{1}}\right)^{2}}
$$

A number of samples with losses ranging from 0.0005 to 5.0 were measured in the permeameter and the resulting data evaluated using eqs (8) and (9), and (18) through (23). The resulting values of $\mu^{\prime}$ and $\tan \delta$ for 5 of these samples are shown in figure 6. Also included are $\mu^{\prime}$ and $\tan \delta$ as measured in a coaxial line. Below $15 \mathrm{Mc} / \mathrm{s}$, samples F3, P1, and P2 could no longer be measured in the coaxial line because of their low resistance. ${ }^{7}$ To increase the resistance to a value within the limits of the measuring system, the volume of the material was increased by adding a number of cores of the same material to the coaxial line. In this way an average value of $\tan \delta$ for each material was obtained at several frequencies below $15 \mathrm{Mc} / \mathrm{s}$. These results are in close agreement with tan $\delta$ obtained by measuring individual samples in the permeameter and evaluating the data with eq (9), the exact expression for $\tan \delta$.

A study of the results from the different equations (with $\mu^{\prime} \cong 4$ to 4,000 and $\tan \delta \cong 0.0005$ to 5.0 ) shows that the equations may be used within the following limitations:

(1) Equation (18) can be used for all values of $\mu^{\prime}$ provided $\tan \delta$ does not exceed approximately 0.1 . For tan $\delta$ greater than $0.1,(18)$ gives values for $\mu^{\prime}$ that are too high.

(2) Equation (22) gave correct results for $\mu^{\prime}$ in the range of $\mu^{\prime}$ and $\tan \delta$ studied. $\quad\left(\mu^{\prime} \cong 4\right.$ to 4,000 and $\tan \delta \cong 0.0005$ to 5.0 ).

(3) Equations (19), (20), (21), and (23) can be used for $\tan \delta$ in the approximate range of 0.1 to 1.0 , with the exception of (23) which can be used up to at least 5.0.

7 The equivalent series resistance of the sample is $\omega \mu^{\prime} L_{a} \tan \delta$. 

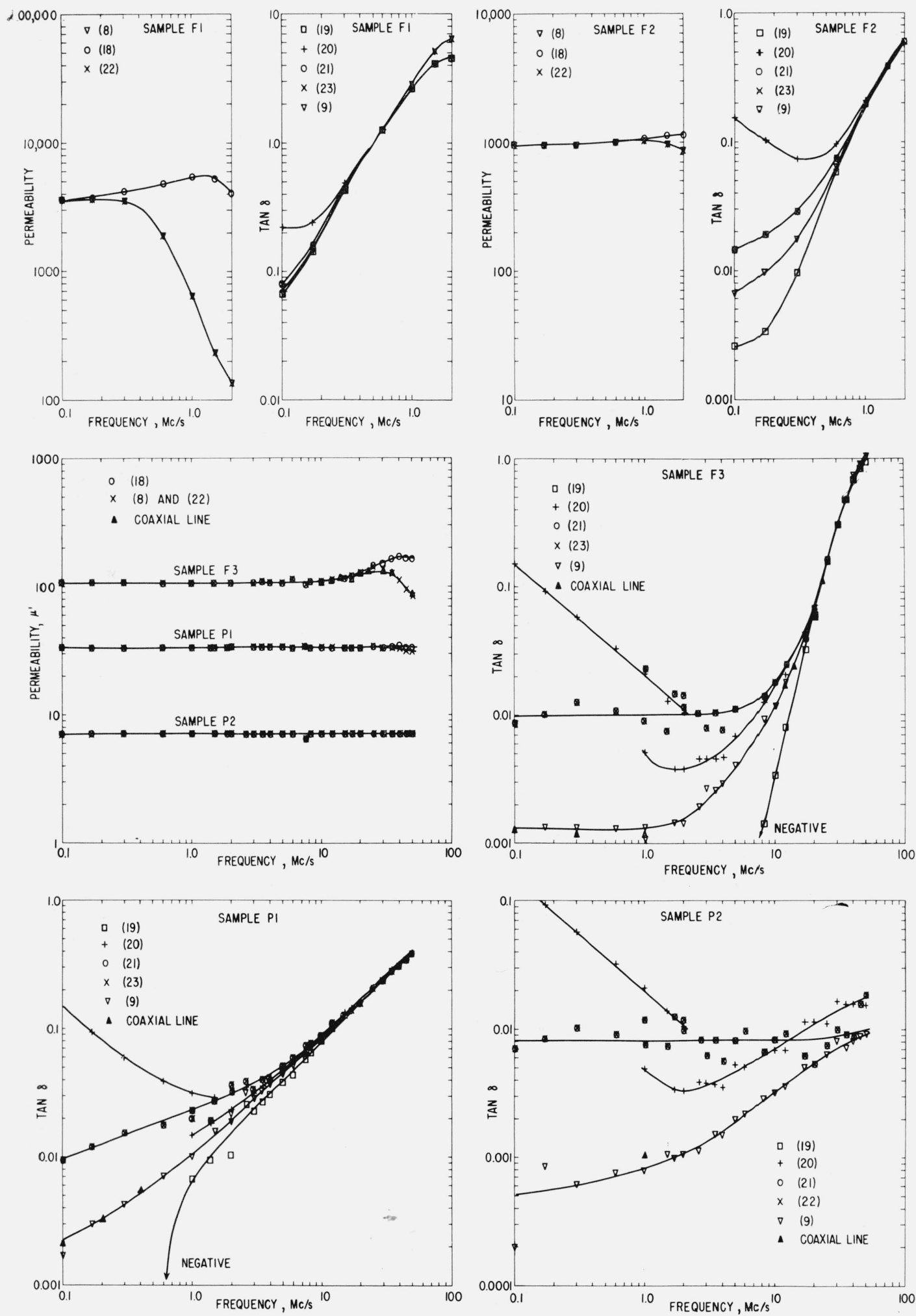

FIGURE 6. Three ferrite samples (F1, F2, and F3) and two powdered iron samples (P1 and P2) measured in rf permeameters on a Maxwell type bridge $(0.1$ to $2.0 \mathrm{Mc} / \mathrm{s})$ and on a $\mathrm{Q}$ meter $(1.0$ to $50 \mathrm{Mc} / \mathrm{s})$.

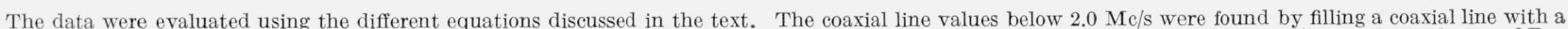

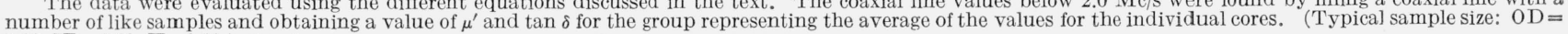
$1.00, \mathrm{ID}=0.60, \mathrm{H}=0.16$ inches.) 
(4) The exact equations (8) and (9) can be used for values of $\mu^{\prime}$ and $\tan \delta$ at least within the range of $\mu^{\prime} \cong 4$ to 4,000 and $\tan \delta \cong 0.0005$ to 5.0 .

(5) The approximate eqs (8a) and (9a) agree with (8) and (9) to better than 1 percent for $\tan \delta<0.1$.

The authors thank Mr. W. A. Pittman for making the many measurements and calculations.

\section{Appendix A. Description of the RF Per- meameter}

The rf permeameter is an impedance transformer. It has a wound powered iron or stable ferrite toroidal core as a primary and a coaxial shorting enclosure as a secondary which envelops both the primary and a toroidal test sample core in such a manner that the magnetic field is concentric with the coaxial structure. Primaries, provided with connectors for terminals at one end of the enclosure, have different input impedances depending upon the frequency of interest and cover a range of at least $20 \mathrm{kc} / \mathrm{s}$ to 50 $\mathrm{Mc} / \mathrm{s}$. The core to be tested is inserted into the permeameter secondary where it is surrounded by a nearly uniform current sheet. Relatively small impedance changes in the secondary are easy to detect at the input to the primary. Because the form of the test core is toroidal, corrections for demagnetization effects are not necessary.

In making measurements, the primary of the permeameter is placed in an arm of an impedance bridge or across the terminals of a $Q$ meter. The input impedance of the primary of the permeameter is measured, first with permeameter secondary open, second with permeameter secondary shorted without a sample, and third with permeameter secondary shorted with either a standard or unknown sample enclosed. From these data, the initial permeability $\left(\mu^{\prime}\right)$ and the dissipation factor $\left(\tan \delta=\mu^{\prime \prime} / \mu^{\prime}\right)$, i.e., the reciprocal of the $Q$ of the material, are derived.

\section{Appendix B. Accuracy Check Using Metal Rings}

At radiofrequencies a metal ring or toroid has an impedance which can be calculated from its physical dimensions and the resistivity of the metal. Such a ring would be an ideal standard of impedance for calibrating the permeameter provided that the impedance of the ring was within the impedance range of the permeameter. It can be shown that the inductance and resistance of a metal ring at radiofrequencies are

$$
\begin{gathered}
L=2(H-\delta) \ln \frac{O D-\delta}{I D+\delta} 10^{-9} \text { henry } \\
R=\frac{\rho}{\pi \delta}\left[\ln \frac{O D-\delta}{I D+\delta}+\frac{(H-\delta)(O D+I D)}{(O D-\delta)(I D+\delta)}\right] \mathrm{ohm}
\end{gathered}
$$

where

$$
\begin{aligned}
& \delta=\frac{1}{2 \pi} \sqrt{\frac{\rho 10^{9}}{f}}, \text { skin depth in } \mathrm{cm}, \\
& \rho=\text { resistivity, } \Omega \mathrm{cm}, \\
& f=\text { frequency in cycles/second, }
\end{aligned}
$$

OD, ID, $\mathrm{H}=$ outside diameter, inside diameter, height in $\mathrm{cm}$.

Several brass and copper rings were made and used in an attempt to calibrate the permeameter, but the results lacked precision. The impedance of the metal rings and the $Q$ of the permeameter with a ring enclosed were too low for accurate determination of the calibration constants $x$ and $y$.

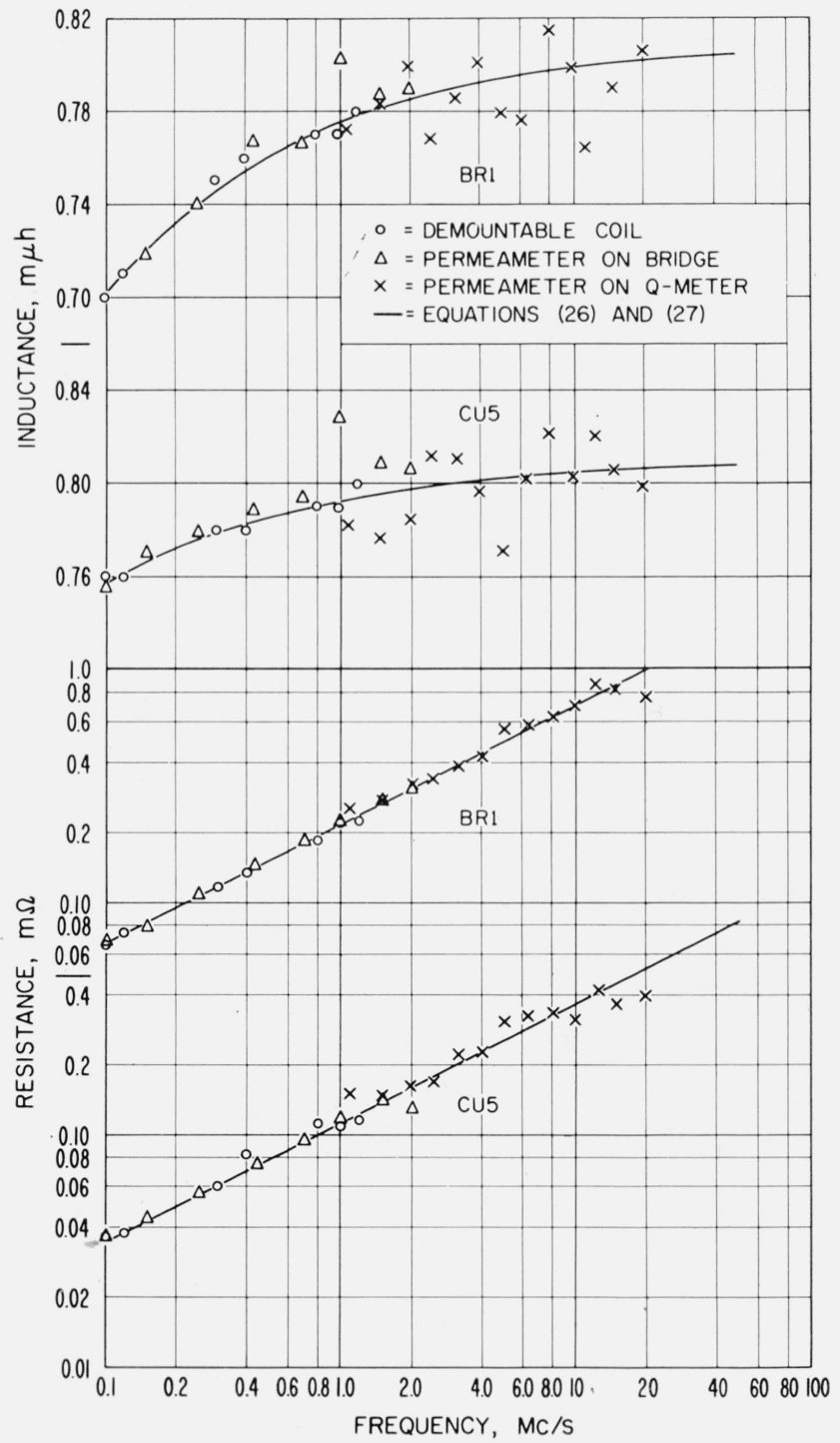

FIGURE 7. Resistance and inductance of a brass (BR1) and a copper (CU5) ring as measured in a demountable coil and in the permeameter.

The solid lines are calculated from equations (26) and (27). 
It was decided that the metal rings would not make good calibration cores, but that they could be used to check the accuracy of the permeameter when using the exact equations. Figure 7 shows the results of the measured values of inductance and resistance versus frequency of two brass and two copper rings of different size. The rings were measured in the permeameter on a Maxwell-type bridge from 0.1 to $1.0 \mathrm{Mc} / \mathrm{s}$ and on a Boonton $Q$ meter 260-A from 1.0 to $50 \mathrm{Mc} / \mathrm{s}$. The $\mathrm{SF}$ core described in part 4 was used as the calibration core. The data were evaluated with the exact equations in the form

$$
R-j \omega L=\omega(x+j y)\left(\frac{Z_{f}-Z_{0}}{Z_{f}-Z_{1}}\right)
$$

The rings were also measured in a demountable coil [5] from 0.1 to $1.0 \mathrm{Mc} / \mathrm{s}$ on the Maxwell type bridge to compare the results of the permeameter and demountable coil with each other as well as with the results from (26) and (27).

As figure 7 shows, the results of the permeameter are in complete agreement with that from the de- mountable coil and from (26) and (27) within the precision of the measuring devices. The precision obtained for both the permeameter and the demountable coil is approximately 20 ph for $L$ and $0.02 \mathrm{~m} \Omega$ for $R$ from 0.1 to $1.0 \mathrm{Mc} / \mathrm{s}$ on the bridge. The precision obtained from the permeameter on the $Q$-meter is approximately $50 \mathrm{ph}$ for $L$ and $0.1 \mathrm{~m} \Omega$ for $R$.

\section{References}

[1] Haas, P. H., A radio frequency permeameter, J. Research NBS 51, 221-228 (Nov. 1953) RP2454.

[2] McKnight, G. P., Permeameter for radio frequencies, Elec. Mfg. 52, No. 4, 150 (Oct. 1953).

[3] Rasmussen, A. L., A. W. Enfield, and A. E. Hess, Advances in the design and application of the radio frequency permeameter, J. Research NBS 56, 261-268 (Mav 1956) RP2673.

[4] Rasmussen, A. L., and A. E. Hess, RF permeameter techniques for testing ferrite cores, Elec. Mfg. 61, No. 5, 86 (May 1958).

[5] Danielson, B. L., and R. D. Harrington, A technique for reducing errors in permeability measurements with coils. Proc. IRE 48, No. 3, 365-366 (March 1960).

(Paper 67C1-121) 


\section{Publications of the National Bureau of Standards*}

\section{Selected Abstracts}

Elastic constants of rutile $\left(\mathrm{TiO}_{2}\right)$, J. B. Wachtman, Jr., W. E. Tefft, and D. G. Lam, Jr., J. Research NBS $66 \mathbf{A}$ (Phys. and Chem.) No. 6, 465 (Nov.-Dec. 1962) 7O cents. The six elastic constants (and six elastic compliances) of rutile were determined in the kilocycle per second frequency range by a resonance method. The standard deviations range from 0.2 percent for $s_{11}$ to 4.3 percent for $s_{13}$.

Reaction of hardened portland cement paste with carbon dioxide, C. M. Hunt and L. A. Tomes, J. Research NBS $66 \mathbf{A}$ (Phys. and Chem.) No.6, 473 (Nov-Dec. 1962) 70 cents.

The effect of age, water-cement ratio, and evaporable water content on the reaction of hardened cement paste with carbon dioxide was investigated, using small cylinders of cement paste. The rate and extent of the reaction are subject to manipulation by varying the evaporable water content of the paste. Pastes of different age and water-cement ratio tend to dry at different rates, and this tendency exerts an important indirect effect on carbonation.

According to the $\mathrm{CO}_{2}-\mathrm{H}_{2} \mathrm{O}$ stoichiometry of carbonation, other phases can react while calcium hydroxide is still present, but the possibility of preferential attack on calcium hydroxide at low levels of carbonation should be considered. Watercement ratio, particularly when the paste is very dense, may make a difference in the relative accessibility of different phases to carbon dioxide.

Reliability of a system in which spare parts deteriorate in storage, G. H. Weiss, J. Research NBS 66B (Math. and Math. Phys.) No. 4, $15 \%$ (Oct.-Dec. 1962) 75 cents.

The problem which we consider in the following paper is the calculation of the lifetime statistics of a component with $n$ spares with the proviso that redundant elements can fail in storage. It is assumed that failed components are instantaneously replaced. Similar models have been considered before in the literature, particularly by Proschan and collaborators, who were interested in determining the optimal spare parts kit for a system of components in series, given a fixed amount of capital to provide the spare parts. If it is assumed that components do not deteriorate in storage then the calculation of the distribution of time to failure is simple since it is just the sum of individual failure times. In the present situation the calculations are somewhat more complicated, and we have only succeeded in finding a solution when the reliability functions for on-line failures and for instorage failures are exponential. In other cases we prescribe algorithms for the solution.

A model for the viscoelastic behavior of rubberlike polymers including entanglement effects, R. S. Marvin and H. Oser, J. Research NBS 66B (Math. and Math. Phys.) No. 4, 171 (Oct.-Dec. 1962) 75 cents.

A model representing the mechanical response of a rubberlike polymer is derived, using the same molecular concepts of entropy elasticity and a viscous parameter expressing interactions between polymer molecules employed by Rouse, Bueche, and Zimm in their molecular theories. Since the model developed here represents the mechanical response of a chain, rather than the chain itself, it can be modified more easily than these strict molecular theories to include effects due to entanglements between chains which modify the character of the viscosity-molecular weight relationship at a critical molecular weight.

This modification is introduced, the results for both steadystate and transient response functions are calculated, and these results compared with experiment for the "Standard" polyisobutylene. The agreement indicates that the same "entanglements," whatever their precise nature, are responsible for the proportionality of viscosity to M3.4 for a high molecular weight polymer, the equilibrium compliance, and the pseudoequilibrium compliance at intermediate times or frequencies.

RF impedance probe measurements of ionospheric electron densities, J. A. Kane, J. E. Jackson, and H. A. Whale, J. Research NBS 66D (Radio Prop.) No.6, 641 (Nov.-Dec. 1962) Yo cents.

The Aerobee-Hi rocket NASA 4.07 obtained vertical electron density profiles in the ionosphere simultaneously by the Seddon $\mathrm{CW}$ propagation technique and by an $\mathrm{RF}$ impedance probe technique. The experimental goal was to assess the performance of the RF probe against the accurate values from the $\mathrm{CW}$ method. In the $\mathrm{RF}$ probe method, the electron density $N$ was derived from the dielectric constant $K$ of the medium at a frequency $f=7.75 \mathrm{Mc} / \mathrm{s}$. If the earth's magnetic field is neglected, the relation between these quantities may be given as $K=1-\left(81 N / f^{2}\right)$. An expression for the dielectric constant including the effects of the earth's magnetic field is derived. The fractional error introduced by neglecting the earth's field is of the order of $\left(f_{H} / f\right)^{2}$ where $f_{H}$ is the electron gyrofrequency.

It was concluded that, with allowance for the positive ion sheath around the rocket, the RF impedance probe can yield reliable values of electron density. These values were obtained from changes in the capacitive part of the probe's impedance. Small, apparently anomalous changes in the resistive part were also observed.

On the geometrical optics of curved surfaces with periodic impedance properties, C. J. Mareinkowski and L. B. Felsen, J. Research NBS 66D (Radio Prop.) No. 6, 699 (Nov.-Dec. 1962) 70 cents.

In a previous publication, a two-dimensional Green's function has been derived for a circular cylinder whose surface impedance around the periphery deviates from a constant value by a sinusoidal variation of small amplitude $\alpha$. Here, this solution is evaluated asymptotically in the illuminated region under the assumption that the eylinder radius is large compared with the wavelength of the incident field. The asymptotic result is interpreted in terms of geometrical optics generalized to apply to cylindrically curved, convex reflection gratings, and comprises the first and higher order diffracted rays associated with a plane grating, together with geometrical divergence coefficients accounting for the surface curvature. General properties of the spectrum of reflected rays are observed. The behavior of the first-order diffracted rays, and in particular their domain of existence as a function of surface periodicity, is discussed in detail.

On the limitations of geometrical optics solutions for curved surfaces with variable impedance properties, C. J. Marcinkowski and L. B. Felsen, J. Research NBS 66D (Radio Prop.) No. 6, 707 (Nov.-Dec. 1962) 70 cents.

In the preceding paper, the authors have presented an asymptotic solution for the field in the illuminated region of a large circular cylinder whose surface impedance around the periphery deviates from a constant value by a sinusoidai variation of small amplitude $\alpha$. To $\mathrm{O}(\alpha)$, the reflected field comprises a specularly reflected ray and two first-order diffracted rays characteristic of a curved convex reflection grating. If the surface impedance varies "slowly," these three rays can be combined into a single specularly reflected ray having a reflection coefficient which depends solely on the local impedance at the reflection point. The "slowness" conditions necessary for the validity of this local reflection principle of geometrical optics are investigated and interpreted in physical terms. The results are presented in a manner which suggests their applicability to general, gently curved surfaces with slowly varying impedance properties. 
Chemistry of cement. Proceedings of the fourth international symposium, Washington, 1960, NBS Mono, 43, Vol. I (Aug. 31, 1962), \$5.75; Vol. II (Sept. 27, 1962), \$5.50. The two volumes are available at $\$ 11.25$ a set.

This two-volume Monograph contains the complete texts of all papers given at the Fourth Internal Symposium on the Chemistry of Cement, held in Washington, D.C., October $2-7,1960$. The publication represents one of the most complete reference works available on the subject, and presents the latest information in most of the fields of cement chemistry research. Topics covered, divided according to session titles: Volume 1, Chemistry of clinker, chemistry of hydration of cement compounds, and chemistry of hydration of portland cement; Volume II, Properties of cement paste and concrete destructive processes in concrete, chemical additions and admixtures, and special cements.

Tables of Eisenstein functions. Vibrational contributions to the thermodynamic functions, J. Hilsenrath and G. G. Ziegler, NBS Mono. 49 (July 12, 1962), \$2.75.

Tables are presented for the contribution of a harmonic oscillator to the free energy function, enthalpy function, entropy, and heat capacity of gases. Dimensionless values of the Planck-Einstein functions are given as a function of $X=H c / k T$ for $X=0.0010(.0001) \quad 0.1500(.001) \quad 4.000(.01)$ $10.00(.2) 16.0$. A second table which gives the contributions in $\mathrm{cal} / \mathrm{mole}{ }^{\circ} \mathrm{K}$ directly as a function of frequency $\mu$, and temperature $T$, was computed using the values 1.43880 for the second radiation constant $h c / k$, and 1.98717 for the universal gas constant $R$. The arguments for the latter table are spaced at 10 wave number intervals from $100 \mathrm{~cm}^{-1}$ to 4000 $\mathrm{cm}^{-1}$.

Bibliography on atomic transition probabilities, B. M. Glennon and W. Wiese, NBS Mono. 50 (Aug. 1, 1962), 35 cents. A bibliography on atomic transition probabilities is presented. The papers are arranged according to elements and stages of ionization, and the method employed and class of transitions are indicated behind each reference. Only articles on discrete transitions, both permitted and forbidden, are listed. Also included is a supplementary list of papers dealing with transition probabilities from a general point of view, a table showing the availability of numerical material on the individual atoms and ions, and a table of conversion factors

Systems of electrical units, F. B. Silsbee, NBS Mono. 543 (Sept. 20, 1962), 30 cents.

The various systems of measurement, with their respective sets of units, used in the literature on electricity and magnetism are described in detail. Their historical development is summarized. The manner in which each is derived from either of the two alternative points of view of the experimentalist and the theoretician is compared and contrasted. The desirability of recognizing both points of view in international standardization, particularly when discussing rationalization, is pointed out. The present status of the absolute measurements on which all electrical units are based is reported, and tables are included for the conversion of equations and numerical values from one system to another.

A survey of the techniques for measuring the radio refractive index, R. E. MeGavin, NBS Tech. Note 99 (May 1962) 30 cents.

The radio refractive index can be measured either directly or indirectly. The former method is utilized by radio frequency refractometers; the latter method involves measurement of temperature, pressure and humidity and conversion to refractive index. In terms of convenience and accuracy the direct method is superior; however, lack of the universal use of refractometers requires the use of weather service type of data for the bulk of refractive index structures. Meteorological sensing is limited mainly by the inaccuracy in measuring humidity which under ideal conditions appears to limit the accuracy to $\pm 1.0 \mathrm{~N}$. Gradient measurements utilizing radiosondes reflects an accuracy no better than $\pm 3 \mathrm{~N}$ units. Radio frequency refractometers are capable of accuracies as much as an order of magnitude better than that achieved by meteorological sensors. Lightweight refractomenters have been devised for balloon-borne and dropsonde measurements reflecting accuracies inferior to the conventional refractometer but superior to the radiosonde.

A tabulation of the thermodynamic properties of normal hydrogen from low temperatures to $540{ }^{\circ} R$ and from 10 to 1500 psia, Supplement A (British units), J. W. Dean, NBS Tech. Note 120A (June 1962) 45 cents.

Pressure, volume, temperature, internal energy, enthalpy, and entropy of normal hydrogen gas have been tabulated along isobars in $2^{\circ} \mathrm{R}$ temperature steps. The range covered is from the saturation temperature to $540{ }^{\circ} \mathrm{R}$ and from a pressure of 10 to 1500 psia. The source of data is Research Paper 1932 of the National Bureau of Standards Journal of Research. The method is described by which the data presented in Research Paper 1932 is reduced to properties directly useful for engineering calculations. A method is also described for estimating the effects of ortho-para compositions upon the tabulated properties.

Tabular values are presented in the dimensional units of the British system. The tabulations are also available in the dimensional units of the metric system as Technical Note No. 120 .

General characteristics of linear strain gage accelerometers used in telemetry, P. S. Lederer, NBS Tech. Note 150 (June 1962) 40 cents.

This paper presents a summary of pertinent information, theoretical and experimental, on the design characteristics, performance capabilities and limitations of strain gage accelerometers used in telemetry. Properties and characteristics of unbonded and bonded types of strain gage accelerometers are discussed.

A general survey of the semiconductor field, G. W. Reimherr, NBS Tech. Note 153 (Aug. 1962) 30 cents.

This survey presents a listing of some of the properties and applications of a number of single-element and binary compound inorganic semiconductors. Brief mention is made of other types of semiconductors (ternary compounds, mixed crystals, alloys, ferrites, and organics). The toxicity problem presented by many semiconductors is noted.

The thermodynamic properties of helium from 3 to $300{ }^{\circ} \mathrm{K}$ between 0.5 and 100 atmospheres, D. B. Mann, NBS Tech. Note 154 (Jan. 1962) 50 cents.

The specific volume, enthalpy, entropy, and internal energy values of helium are presented in tabular form as functions of pressure and temperature.

Data are tabulated in one degree Kelvin increments for forty isobars between 0.5 atmosphere and 100 atmospheres. A comparison with previously published data is made where applicable.

An expression is presented which represents the pressuredensity-temperature surface based on previously published data.

The tabulation is presented in the dimensional units of the metric system, but is also available in the dimensional units of the British system (Supplement A).

The heat capacity of diamond at high temperatures, A. C. Victor, J. Chem. Phys. 36, No. 7, 1903-1911 (A pr. 1962). The enthalpy of gem diamonds has been measured from 273 to $1073^{\circ} \mathrm{K}$ using a "drop" method and a Bunsen ice calorimeter. The derived heat-capacity values, which are believed to be accurate to $\pm \mathbf{0 . 5}$ percent, are used to calculate the thermal functions of diamond above $298.15^{\circ} \mathrm{K}$. Values of $\mathrm{C}_{\mathrm{v}}^{\mathrm{O}}$ (harmonic) derived from the present investigation and recent measurements of the thermal expansion and the elastic constants of diamond are compared with theoretical treatments. Reasonably good agreement in the temperature range of this study can be obtained with a single Debye function $\left(\Theta_{D}=1860\right)$ obtained from the measured elastic constants. Extrapolation of the data gives $\theta_{\infty}=1880 \pm 10$.

Millimeter wave techniques, W. Culshaw, Book, Advances in Electronics and Electron Physics XV, 197-263 (Academic Press, Inc., New York, N.Y., 1961).

The importance of millimeter waves both in research and in technology is outlined, and the difficulties experienced in the exploitation of these short wavelengths are made evident. 
Considerable attention is given to transmission and measurement problems, since conventional waveguide methods have serious limitations at short $\mathrm{mm}$ wavelengths. Optical and quasi-optical methods are discussed, and applications of $\mathrm{mm}$ wave interferometers and a $\mathrm{mm}$ wave spectrometer are considered and diffraction effects treated in detail. The great potential use of the $\mathrm{mm}$ wave Fabry-Perot interferometer in precision measurements, and in maser research is made evident. Total reflection phenomena at $\mathrm{mm}$ wavelengths are presented and applications such as attenuation standards, phase changers, and polarizers are discussed. A re-entrant biconical spherical resonator is considered for operation at $\mathrm{mm}$ and sub-mm wavelengths, at high orders of interference. Expressions for the $\mathrm{Q}$ and shunt impedance are given, and results indicate that it could bave direct application to the $\mathrm{mm}$ wave generation problem, and to solid state research at these wavelengths. Finally some practical aspects of $\mathrm{mm}$ wave detection and possible levels of sensitivity are given, together with some concluding remarks on millimeter wave research.

Plastics, G. M. Kline, Encyclopedia Americana XXII, 221229 (1962 Ed.).

The article currently published in the Encyclopedia Americana has been revised and expanded to include new developments in materials, processes, and applications. New sections have also been added on stereospecific polymerization, irradiated plastics, and graft and block copolymers.

The influence of temperature and pressure on the rheological properties of polymers, R. S. Marvin, J. Japan Soc. Testing Materials, Rheology Issue 11, 303-307 (May 1962).

The influence of temperature and pressure on viscosity and their corresponding influence on time dependent rheological properties is reviewed in terms of the free volume theory. Measurements obtained at the National Bureau of Standards on the effect of pressure on the dynamic bulk nodulus of natural rubber and poly (vinyl acetate) are used to illustrate the usefulness of the free volume concept and to give some clues as to its validity. The results for natural rubber seem to agree very well with the predictions of the free volume theory; those for poly(vinyl acetate) show an unexplained discrepency which indicates the need for further studies of other polymeric systems.

Extension of the Flory-Rehner theory of swelling to an anisotropic system, S. D. Bruck, J. Polymer Sci. 55, 29-31 (Dec. 1961)

The Flory-Rehner treatment of isotropic swelling of crosslinked amorphous networks has been modified to apply to oriented, semi-crystalline structures. The new parameters introduced can be readily determined from the dimensional changes of small segments of fibers in a suitable solvent using a microscope equipped with a micrometer eyepiece or with a photomicrograph assembly. Unlike other methods, this technique enables the attainment of swelling equilibria usually within 30 minutes. Preliminary experiments conducted on a series of crosslinked fibers substantiate the validity of this modification of the Flory-Rehner equation.

The international standard of light, R. P. Teele, J. Opt. Soc. Am. 5\%, No. \%, 826 (July 1962).

In 1931 Wensel et al., reported the practical realization of the suggestion, made in 1908 by Waidner and Burgess, that a blackbody radiator at the freezing point of pure platinum be used as a standard of light. Subsequently such a standard was adopted internationally, effective January 1, 1948. From 1957 to the present time investigations of factors affecting the reproducibility of the standard have been conducted at the National Bureau of Standards. The previous work was extended to include crucibles and sight tubes of different dimensions and immersed to various depths, and the use of various freezing patterns. The application of corrections for the necessary viewing aperture, for the temperature drop in the walls of the sight tube, and for the unimmersed portion of the sight tube, enable us to evaluate the ideal blackbody radiator from observed values obtained with practical radiators. Appropriate modification of the freezing pattern yields improved precision. It is found that the standard is reproducible to well within 0.1 percent.
It is planned to present a complete discussion and results in the Journal of Research of the NBS.

Polymer degradation (by heat, oxidation and radiation), in unsolved problems in polymer science, L. A. Wall, ASD Tech. Report 62-283, pp. 32-36 (Mar. 1962).

The Committee of Macromolecular Chemistry of the National Academy of Sciences-National Research Council has requested this Survey of the Problems in Polymer Degradation.

Infrasonic pressure waves associated with magnetic storms, P. Chrzanowski, J. M. Young, G. Greene, and K. T. Lemmon, J. Phys. Soc. Japan 1\%, Suppl. A-II, 9-13 (1962).

Pressure waves with predominant periods between 20 and 80 seconds and amplitudes up to $8 \mathrm{dyne} / \mathrm{cm}^{2}$ have been recorded with a quadrilateral microphone array near Washington, D.C., during intervals of high magnetic activity. These waves have a trace velocity along the earth's surface higher than the local speed of sound and show diurnal-directional properties consistent with a source on the night side of the earth. A high degree of association with large values of the planetary magnetic index $K_{p}$ hs been established.

Characterization of textile yarns for use under ballistic impact conditions, J. C. Smith, Proc. Symp. Personnel Armour, U.S. Naval Research Laboratory I, 1-21 (Oct. 4-5, 1961).

This paper shows how textile materials for personnel armor can be selected using criteria derived from theories on transverse impact of long textile yarns. These theories introduce the concepts of longitudinal and transverse critical velocities defined as velocities just sufficient to cause immediate rupture in a yarn struck transversely or impacted in tension. An extension of the theory shows that the longitudinal and transverse critical velocities of a textile yarn depend upon the shape of its stress-strain curve, and are greatest when the curve is linear. An expression is derived for the initial rate at which a yarn absorbs energy from a projectile impacting it transversely. Arguments based on this expression suggest that a yarn most suitable for use in personnel armor should have a high transverse critical velocity and a high breaking tenacity.

Critical velocity estimates are calculated for some textile yarns using stress-strain data obtained at impact speeds near $45 \mathrm{~m} / \mathrm{sec}$. The longitudinal critical velocities range in value from $165 \mathrm{~m} / \mathrm{sec}$ for acetate yarn to approximately 300 $\mathrm{m} / \mathrm{sec}$ for some vinal, rayon tire cord, acrylic and nylon yarns. Transverse critical velocities for these materials are two to three times higher.

Effect of gamma radiation on chemical structure of plastics, V. J. Krasnansky, M. S. Parker, and B. G. Achhammer, SPE Trans. 1, 133-138 (July 1961).

Twelve plastics representing various chemical structures were studied as part of a program to determine the utility of plastics as packaging materials in the high energy radiation preservation of food. The plastics were exposed to selected dosages of Cobalt-60 gamma radiation, in vacuum and in air. Gas evolution and changes in infrared spectra as a result of irradiation were used to hypothesize the relative stability of these plastics to irradiation. On the basis of these criteria it was found that plastics containing conjugated ring systems, ionic linkages, and chlorine in side groups were the most stable.

Thermal degradation of polymers at temperatures up to $1200^{\circ}$ C, S. L. Madorsky, Soc. Chem. Ind. Mono. No. 13, 60-74 (1961).

A study was made of the thermal degradation of polymers in a vacuum and in some cases in helium at atmospheric pressure, using 10 to $50 \mathrm{mg}$ samples. Polymethylene, a noncrosslinked polymer, when heated for about half an hour in a vacuum or in helium at $500^{\circ} \mathrm{C}$, vaporizes without leaving a residue. The volatile products consist of a series of saturated and unsaturated hydrocarbons of various molecular weights. At $800^{\circ} \mathrm{C}$ and higher, pyrolysis gives similar results; however, the products are more fragmented, and the higher the temperature and pressure the greater is this fragmentation. Polytrivinylbenzene, which is a highly crosslinked polymer, and poly(vinylidene fluoride), which is one that develops cross- 
linkings during pyrolysis, both yield on heating in a vacuum at any pyrolysis temperature various volatile fragments and a more or less carbonized residue. Here too, as in the case of polymethylene, a higher temperature produces greater fragmentation of the volatile products. The more volatile products were analyzed by mass spectrometry, and the less volatile products were tested for their average molecular weight by a microcryoscopic method. Elemental analysis of residues were made by a microchemical method.

Charge-storage techniques for pulse-height analysis, L. Costrell and R. E. Brueckman, Nuclear Electronics (Intern. Atomic Energy Agency) II, 29-39 (1962).

The low duty cycles of many pulsed accelerators make necessary high pulse rates within the bursts in order to accumulate adequate data in a reasonable time. Not only do economic factors, as influenced by expensive machine time, dictate the use high pulse rates, but purely technical considerations often make experiments unfeasible unless the pulses per burst are so numerous as to exclude the use of conventional pulse-height analyzers. For these reasons much effort has been devoted to development of high speed pulse-height analyzers for use with pulsed accelerators. Much of this work has been directed toward producing what we term a "charge-storage analyzer" based on work conducted at the National Bureau of Standards. We have developed a chargestorage analyzer that is in operation with the NBS $180 \mathrm{Mev}$ synchrotron on a nuclear absorption experiment for which the obstacles would otherwise be formidable. The analyzer uses temporary electrostatic storage for the accumulation of pulse-height data during the machine bursts. During the dead intervals between bursts the contents of the temporary storage are analyzed and transferred into a convential magnetic core memory. The use of this technique for nanosecond pulses is discussed and data is presented to show its feasibility.

Glass Dewars for optical and other studies at low temperatures, L. J. Schoen and H. P. Broida, Rev. Sci. Instr. 33, No. 4, 470-473 (Apr. 1962).

A small, rugged glass Dewar using a liquid nitrogen cooled metal shield is described. This Dewar is relatively inexpensive to construct and to modify, stores helium with only a moderate loss rate, and can be adapted for a wide variety of low temperature experiments. Two other Dewars, in which vapor-cooled radiation shields replace liquid nitrogen cooled shields, also are described. Helium loss rates show that a liter of liquid helium will keep these Dewars at $4^{\circ} \mathrm{K}$ for about 5 to $10 \mathrm{br}$.

Distillation analysis, R. T. Leslie and E. C. Kuehner, Anal. Chem. Suppl. 34, No. 5, 50R-56R (A pr. 1962.).

The world literature concerning laboratory distillation and related subjects that appeared in 1958-1959 is summarized. The survey covers the construction and testing of laboratory stills for use at atmospheric and low-pressure, and for microdistillation. Applications to special problems, both organic and inorganic, are discussed briefly, and theoretical and mathematical papers concerning column design and operation are mentioned. Studies of the vapor-liquid equilibria of azeotropic and nonazeotropic systems are summarized.

Displacement and strain-energy distribution in a longitudinally vibrating cylindrical rod with a viscoelastic coating, P. Hertenlendy, J. Appl. Mech. 29, Series E, 47-52 (Mar. 1962).

A numerical solution by R. M. Davies of the Pochhammer frequency equation is used to determine the displacement and strain-energy distribution across the cross section of an infinite elastic circular cylindrical rod for a number of wave lengths of the first, second, and third modes of symmetrical longitudinal wave propagation. With these results the effect of a thin uniform layer of viscoelastic material is investigated. The four viscoelastic parameters of the coating are reduced to one in the definition and computation of upper and lower bounds of the loss factor, and the application of results to experimental work is discussed.

Catalytic effects of thermocouple materials, L. O. Olsen, $S A E$ J. Paper No. 524G, 70, No. 5, 94 (May 1962).
It has long been recognized that under some conditions certain noble metal thermocouples produce erroneous indications when immersed in gas streams containing oxygen and combustible gases. These errors have been shown to be caused by catalysis of the gaseous mixture on the surfaces of the thermocouple elements. The object of this investigation was to determine the magnitude of the catalytic effects of all of the commonly used thermocouple materials in lean mixtures of hydrogen, carbon monoxide, propane, and methane in air. The effects of catalysis were determined under three different experimental methods.

Wires of platinum, palladium, iridium, platinum plus $15 \%$ iridium, and the two elements of the Platinel thermocouple were found to catalyze the combustion of mixtures of hydrogen, carbon monoxide, and propane in air. Combustion of methane-air mixtures was not initiated by these materials at temperatures up to $1800^{\circ} \mathrm{F}$. Experiments with gold, silver, Chromel, Alumel, and constantan wires showed no catalysis of any mixture at temperatures of the wires up to $1800^{\circ} \mathrm{F}$. Base-metal thermocouples are therefore recommended for accurate determinations of temperatures of gaseous mixtures containing combustible materials.

Characteristics of some air-turbine handpieces, D. F. Taylor, R. R. Perkins, and J. W. Kumpula, J. Am. Dental Assoc. 64, No. 6, 794-805 (June 1962).

A method and equipment were developed for the simultaneous measurement of the speed and torque of dental air turbine handpieces. The power output characteristics of several models of handpieces were studied under a variety of conditions. The effect of air pressure upon speed and torque, and some effects of instrument size and balance upon speed were investigated. Increased air pressure was found to increase both the maximum speed and maximum torque attained but to be more effective in increasing torque. Within clinical limits, the size of the instrument was found to have negligible effect upon power output in comparison to the effect of dynamic balance.

Tensile shear strength of adhesive bonded metals as a function of the rate of loading, D. A. George, H. R. Butzlaff, and J. Mandel, Symp. on Adhesion and Adhesives, Am. Soc. Testing Materials Spec. Tech. Publ. No. 2'y1, 47-53 (1961).

A round-robin test program was devised by ASTM Committee D-14 on Adhesives to study the effects of the rate of loading on the ultimate tensile shear strength of metal-to-meta] adhesive-bonded lap-shear specimens. Two metals, three adhesives, two overlap lengths and four rates of loading were studied. The tensile shear specimens tested at rates of stressing from 600-2000 psi per minute showed very little change in strength due to the rate of stressing. For a given rate of stressing the rate of strain which was observed by changes in crosshead speed increased as the modulus of elasticity of adhesives decreased. It is not possible, therefore, to express one rate of stressing as being equivalent to a particular rate of strain for adhesives that have different moduli of elasticity.

Vacuum system for use with a microbalance, G. F. Rouse, Book, Vacuum Microbalance Techniques, ed. R. F. Walker, 2, 59-69 (Plenum Press, Inc., New York, N.Y., 1962).

A vacuum system constructed for use with a fused-silica torsion microbalance is described. Recent developments in high vacuum apparatus and technique are incorporated into its design. The system can be outgassed at $425^{\circ} \mathrm{C}$ and can be used in connection with experiments which must be carried out at elevated temperatures. Its use makes it possible to perform an experiment under very clean conditions and at pressures less than $10^{-8} \mathrm{~mm} \mathrm{Hg}$.

\section{Creep of pure-gum rubber vulcanizates from indentation-} time measurements, L. A. Wood and F. L. Roth, Rubber Tech. Conf. (London, England, 1962).

The compliance $J$ (limit of the ratio of strain to stress at zero deformation) has been determined from measurements of the indentation of a flat rubber surface by a rigid sphere, as a function of time $t$ and temperature $T$. The results are subjected to two successive operations: (1) $J$ is multiplied by the absolute temperature $T$ and (2) an empirically-determined quantity is added to the logarithm of the time at each 
temperature to make the values of $J T$ agree as well as possible. For natural rubber from $25^{\circ}$ to $-40^{\circ} \mathrm{C}$ of the shift required appears to correspond to a constant "activation energy" of $38 \mathrm{kcal} / \mathrm{mole}$; from $-40^{\circ}$ to $-60^{\circ} \mathrm{C}$ the shift is in quite good agreement with that predicted by the equation of Williams, Landel, and Ferry. Butyl rubber vields an activation energy of $20 \mathrm{kcal} / \mathrm{mole}$, while styrenebutadiene rubber gives a value of $22 \mathrm{kcal} / \mathrm{mole}$. The resulting curve of $J T$ against $\log t$ shows a sigmoid form with an increase of slope over 2-3 decades and a decrease at higher values. There is usually an extended region of nearly constant slope corresponding to the conditions of normal use of rubber products. For natural rubber this slope is $1-2 \%$ per decade; for the synthetics it is appreciably higher, reaching a value of $15 \%$ per decade for nitrile rubber.

The ideal Lovibond color system, D. B. Judd, G. J. Chamberlin, and G. W. Haupt, J. Opt. Soc. Am. 52, No. 7, 813-819 (July 1962).

Lovibond red, yellow, and blue glasses, widely used as color standards in industry, are assigned numerals in accord with the basic plan of marking each glass with the number of unit glasses of the same type through which light must be passed to produce its color. It is possible to compute from the spectral transmittances of the unit glasses defining the Lovibond scales the CIE specification of the color produced by all combinations of any number of unit glasses. Such specifications were computed in 1939 not only for all ideal red, yellow, and blue Lovibond glasses illuminated by CIE sources B (representing noon sunlight) or C (representing average daylight) but also for two-part (red-yellow, yellowblue, or blue-red) combinations thereof. The present paper gives the results of such computations for CIE source A (representing gas-filled incandescent lamps). Although actual Lovibond glasses must unavoidably depart somewhat from this definition of the ideal Lovibond system, the computed color specifications serve to indicate with good reliability not only the CIE specification of the color produced by single glasses and two-part combinations, but also the choice of Lovibond glasses required to produce a color of any desired chromaticity within the gamut of the system.

Single-trace sweep adapter for transistor-curve tracers, L. J Swartzendruber, Rev. Sci. Instr. 33, No. 5, 560-562 (Aug. 1961).

A simple relay circuit, adaptable to curve tracers, that provides a single-trace sweep is described. The adapter allows the low-frequency current-voltage characteristics of many devices to be observed at high currents without large heating effects.

Proton magnetic resonance in clay minerals, R. L. Blaine, Highway Research Board Bull. No. 287, 44-55 (June 1962). Energy absorption line widths at the proton resonance frequency associated with free water $\left(\mathrm{H}_{0}\right)$ were determined for a number of clays and related materials at room temperature. The line widths were calculated from the horizontal distance between the peaks of the maximum and the minimum of the derivative absorption curves obtained with a 1720-gauss proton-magnetic-resonance apparatus. Line widths in the order of decreasing proton mobility were found to be approximately three gauss for pyrophylites, six gauss for kaolins and halloysites, nine gauss for a sepiolite, and eleven to twelve gauss for a bayerite and a bauxite. Illites and montmorillonites gave only narrow line widths ( 0.3 to 0.7 gauss) in the semi-dry state, but exhibited some less mobile hydrogen (line width of 2-3 gauss) after drying at $200^{\circ} \mathrm{C}$. Except for bayerite, bauxite, and sepiolite, the clays did not exhibit the wide lines normally associated with either hydroxide groups or water of crystallization or as determined for brucite and gibbsite. A sample of montmorillonite frozen with liquid nitrogen and slowly thawed in the apparatus indicated that greatly increased proton mobility began at about $-70^{\circ} \mathrm{C}$.

Ultra-high vacuum ultraviolet monochromator, L. Marton, J. A. Simpson, J. A. Suddeth, and L. B. Leder, 1961 Trans. 8th Natl. Vacuum Symp., $2 d$ Intern. Congress, Ed. L. E. Prauss, P. 633-639 (Pergamon Press, Inc., New York, N.Y., 1962).
A 1-meter, normal incidence vacuum ultraviolet monochromator having a sample chamber pressure of approximately 1 $\mathrm{x} 10^{-9} \mathrm{~mm} \mathrm{Ho}$ is described. The entrance and exit slits are on the Rowland circle while the center floats. Wavelength is scanned by moving the grating along the circle. All moving parts are external to the vacuum chamber. The high vacuum conditions are obtained by several stages of differential pumping from the lamp housing to the sample chamber. The entire monochromator is of stainless steel with welded joints. Interesting vacuum features are the flange design, liquid nitrogen traps and rotary sea.

Constitution diagram for $16 \% \mathrm{Cr}-2 \% \mathrm{Ni}$ stainless steel, C. R. Johnson and S. J. Rosenberg, Trans. Quart. Am. Soc. Metals 55, No. 2, 27\%-286 (June 1962).

A constitutional diagram was constructed for the $16 \% \mathrm{Cr}-2 \%$ Ni stainless steels containing up to 1.23 percent carbon, from data obtained by metallographic examinations, thermal analysis, dilatometry, X-ray diffraction, microhardness measurements, and electron microscopy.

Effect of surface roughness on the oxidation rate of iron, A. G. Eubanks, D. G. Moore, and W. A. Pennington, $J$. Electrochem. Soc. 109, No. 5, 382-389 (May 1962)

An investigation was made of the effect of surface roughness on the oxidation rate of iron in air at $800^{\circ} \mathrm{C}$. Specimens of ingot iron were grit blasted to give surfaces of different textures. The roughened specimens were found to oxidize more slowly than smooth ones, the difference in rate becoming greater with increasing roughness. The smooth specimens oxidized parabolically with a certain rate constant at the beginning; however, with continued oxidation, roughness developed on the metal surface and a change in the rate constant occurred. Specimens of high-purity iron with smooth surfaces, on the other hand, not only remained smooth throughout a three-hour oxidation period, but they also oxidized parabolically with a single rate constant.

It was found that the reduction in rate due to roughening was not caused by surface contamination, or by surface cold work, but by voids that form in the scale layers on roughened surfaces. These voids apparently act as diffusion barriers for iron ions and, thereby, lower the rate at which roughened specimens oxidize.

On the theory of diffraction grating interferometers, $\mathrm{H}$ Mendlowitz and J. A. Simpson, J. Opt. Soc. Am. 52, No. 5 , 520-524 (May 1962).

One-dimensional diffraction-grating theory is developed in vector notation. First-order expressions are derived for the effects of the rotation of the grating about an arbitrary axis upon the diffracted beam. These results are applied to the three-grating interferometer whose characteristics are given in some detail. Generalization to moiré patterns or to any number of gratings with arbitrary separations is indicated.

Effect of oleophobic films on fatigue crack propagation, W. L. Holshouser and H. P. Utech, Am. Soc. Testing Materials Proc. 61, 749 (1961).

Sharply notched rotating beam specimens were used to evaluate the effect of oleophobic films formed by dodecyl alcohol on the rate of fatigue crack propagation in 4340 steel, 17-7 PH stainless steel, 6061-T6 aluminum alloy, and a copper $1.75 \%$ beryllium alloy. The number of cycles required to propagate the crack was increased by the presence of the organic compound by factors ranging from 1.4 to 5.0. This effect is attributed to the ability of compounds of this type to form films that protect the metal from oxygen and water vapor in the atmosphere.

Strange sounds in the atmosphere, Part II, R. K. Cook and J. M. Young, Sound-Its Uses and Control 1, No. 3, 25-33 (May-June 1962).

This is the second installment of the popular-scientific account whose first installment was prepared about two months ago. We describe infrasonic waves associated with microbaroms, earthquakes, magnetic storms, and tornados. Material for the second article is drawn from the open technical literature, including scientific papers in Helvetica Physica Acta, Archiv fur Meterologie usw., Nature, etc. 
Time resolved electron optical image of a pulsed atomic beam in flight, L. Marton, S. R. Mielczarek, and D. C. Schubert, J. Appl. Phys. 33, No. 4, 1613-1614 (Apr. 1962.)

The electron optical schlieren method for study of gas behavior at very low pressures has been applied in stroboscopic fashion to produce photographs of chopped atomic beam pulses in flight. A photograph is shown of a cadmium atomic beam pulse moving at approximately 300 meters/sec. with maximum atomic density corresponding to about $2.10^{-6} \mathrm{~mm} \mathrm{Hg}$ equilibrium pressure. The potential usefulness of this technique for study of accommodation coefficients on aerodynamic surfaces is described briefly.

Second breakdown in transistors, H. A. Schafft and J. C. French, IRE Trans. Electron Devices ED-9, No. 2, 129-136 (July 1962).

"Second breakdown" in transistors has been characterized as an abrupt reduction in $\mathrm{V}_{\mathrm{CE}}$, at a collector current designated by $I_{M}$, when the transistor is swept through its $V_{C E}$ vs $I_{C}$ characteristics. A critical review of the literature concerning this phenomenon and a more complete description of its characteristics are given. It appears that "second breakdown" is a more fundamental property of the transistor than has previously been thought. Each of the mechanisms thus far considered in the literature, in particular the "pinch-in" effect and $p-n-p-n$ action, has been examined and found inadequate. The apparent dependence of the initiation of the phenomenon on the quantity of energy absorbed, and on the ambient temperature, indicates that it may be related to some thermal mechanism. This points to the importance of examining "second breakdown" in terms of energy dissipated rather than in terms of voltage or current as has been done to date.

Preservation of edge detail in metallography, W. P. Hayes, Jr., N. Tighe, and H. B. Kirkpatrick, Metal Progress 81, No. 3, 112 (Mar. 1962).

Extremely fragile surface layers have been retained on metallographic sections as the result of the described modified version of a well known technique.

Microsize magnetic field probes with axial symmetry, C. A. Shiffman, Rev. Sci. Instr. 33, No. 2, 206-207 (Feb. 1962).

Magnetic field probes occupying less than $10^{-8} \mathrm{ec}$ and having axially symmetric response have been developed for use at liquid nitrogen temperatures and below. The probes are made by drawing a microscopic boule of bismuth from the melt, using a wire which ultimately serves as a pair of leads at one end. A second wire is fused to the other end by ohmic heating.

Optical studies at high pressures using diamond anvils, C. E. Weir, A. Van Valkenburg, and E. Lippincott, Book, Modern Very High Pressures Techniques, ed. R. H. Wentorf, Jr., p. 51-69 (Butterworth \& Co., London, England, 1962.)

A pressure cell capable of maintaining pressures up to 160,000 atmospheres has been constructed using a pair of type II diamonds for studies in the infrared, visible and ultraviolet spectrum. Temperature variations from $175^{\circ}$ to $-30^{\circ} \mathrm{C}$ can be obtained with the cell. Major effects observed in the infrared spectrum of substances under pressure include shifts in absorption bands to both higher and lower frequencies, occurrence of new band as well as elimination of existing bands, the splitting of bands and changes in apparent band intensities. Examples of these effects using the infrared spectra of sodium nitrite, calcite, succinic acid, ice and ferrocene are given.

Stress-strain relationships in yarns subjected to rapid impact loading. 9. Effect of yarn structure, J. C. Smith, J. M. Blandford, P. J. Shouse, and K. M. Towne, Textile Res. J. 32, 472-480 (June 1962).

Samples of high-tenacity deacetylated cellulose acetate yarn were braided or plied and twisted by various amounts. Stress-strain data were obtained on these yarns at conventional rates of straining and under conditions involving transverse and longitudinal impact at velocities of about $40 \mathrm{~m} / \mathrm{sec}$. Strain wave propagation velocities were also measured. The effects of twisting and braiding were the same at high rates of straining and at conventional rates of straining. The addition of twist or braid caused the following effects. The initial slope of the stress-strain curve and the strain wave propagation velocity decreased. The bend in the curve at the yield stress became less sharp so that the stress-strain curve became more linear. The breaking tenacity decreased and the breaking elongation increased. The work required to break unit mass of yarn material remained unchanged. The calculated value of the longitudinal critical velocity at which a specimen breaks immediately upon impact in tension remained unchanged. Calculated transverse critical velocities tended to decrease as the yarn was twisted or braided.

Stress corrosion of high strength case aluminum alloys, F. M. Reinhart and W. F. Gerhold, Corrosion 18, No. 4, 158 (A pr. 1962).

The unsatisfactory performance in marine environments of high strength sand cast 220-T4 aluminum alloy in vital load carrying applications and the paucity of published information on the heat treatment and resistance to stress corrosion cracking of the alloy prompted this investigation. The purpose was twofold: to determine whether variations in the heat treatment of 220 alloy would improve its resistance to stress corrosion cracking; and to compare the stress corrosion resistance of other high strength cast alloys with that of the $220 \mathrm{~T}-4$ alloy. Specimens of the alloys were stressed at 75 percent of their yield strengths while being intermittently immersed in a sodium chloride-hydrogen peroxide solution. The period of exposure was usually 60 days unless earlier failure occurred. Variations of magnesium contents between 9.1 and 12.7 percent did not affect the low resistance of alloy 220-T4 to stress corrosion cracking. Slow quenching from the solution heat treating temperature slightly improved the resistance of alloy 220-T4 to stress corrosion cracking. A sensitizing treatment or prolonged natural aging rendered the alloy more susceptible to stress corrosion cracking. The resistance to stress corrosion cracking of alloys A356-T61 and 357-T6 was rather uniform and was considerably better than that of 220-T4 alloy. The resistance to stress corrosion cracking of the other alloys investigated was poor.

Phase-modulated calibrator for testing phase meters, M. C. Thompson, Jr., Rev. Sci. Instr. 33, 563-564 (May 1962).

A device is described which may be used to measure the frequency response characteristics of phase meters, both electronic and electro-mechanical.

A procedure for estimating eigenvalues, N. W. Bazley and D. Fox, J. Math. Phys. 3, 469-471 (May-June 1962).

A new procedure is given for calculation of lower bounds to the eigenvalues of self-adjoint operators. Calculation of the lower bounds is reduced to the solution of linear algebraic problems.

Physical standards of emittance and reflectance, J. C. Richmond (Proc. Conf. Radiative Transfer from Solid Materials, Boston, Mass., Dec. 12-13, 1960), Book, Radiative Transfer from Solid Materials, ed. H. H. Blau, Jr., and H. Fischer, Sec. III, pp. 142-153 (The Macmillan Co., New York, N.Y.', 1962).

The work being done at the National Bureau of Standards on the development of specimens stable in emittance is briefly described. The fundamental laws of radiation involved in the measurement of emittance are reviewed and a limited glossary of terms is given.

The reflectance standards issued by the National Bureau of Standards are also briefly described.

A combined analog-digital differential analyzer (CADDA), W. D. Urban, W. R. Hahn, Jr., and H. K. Skramstad, Proc. Combined Analog Digital Computer Systems Symp., Phila., Pa., Dec. 1960, 2d item (1960).

In a paper presented at the $1959 \mathrm{EJCC}$, one of the authors described a concept of using both analog and digital techniques to produce a differential analyzer which combines the analog advantages of high speed and continuous representation of variables with the digital capability of high precision and large dynamic range. This paper deals with a study of the problems in the design, construction, and use of integrators 
and multipliers employing this concept. The mathematical basis for the design is reviewed, and the construction and operation of the equipment is described.

Some properties of dirty contacts on semi-conductors and resistivity measurements by a two terminal method, G. G. Harman and T. Higier, J. A ppl. Phys. 33, 2198 (July 1962). The surface and bulk properties of semiconductors have been studied by a two-terminal method using dirty contacts. These contacts are defined as ones that are easily applied and removed and that are separated from the bulk by surface states, oxides, adhered gasses and chemical films. The method essentially involves measuring the resistance-voltage characteristics from the millivolt range up to about $100 \mathrm{v}$. In the process it is possible to separate the bulk from the surface effects, calculate the surface barrier height and thickness from tunneling equations, and determine whether the barrier is a surface film or due to metal-semiconductor contact potential difference. In addition the resistivity can be measured for difficult materials such as SiC and GaAs. The effect of work-damaging or etching the semiconductor surface can be readily evaluated. Various possible electrode systems are discussed. Efforts were concentrated on silicon carbide and silicon, but the techniques are applicable to all types of semiconductors.

A property of linear frequency modulation, A. J. Goldman, Proc. IRE 50, No. 7, 1711 (July 1962).

(A fact useful in connection with chirp radars is that a linear FM signal of arbitrary envelope, when passed through a suitable network with linear delay characteristic, suffers a reversal of the linear FM and a Fourier transformation of the functional form of the envelope. It is shown here that no other FM signal and delay network are related in this way, i.e., in respect to Fourier transformation of the arbitrary envelope, reversal of a summand of the input phase, and reproduction of the complementary summand.)

The thermal properties of powder insulators in the temperature range $300^{\circ}-\mathbf{4}^{\circ} \mathbf{K}$, D. Cline and R. H. Kropschot, (Proc. Conf. Radiative Transfer from Solid Materials, Boston, Mass., Dec. 12-13, 1960), Book, Radiative Transfer from Solid Materials, ed. H. H. Blau, Jr., and H. Fischer, Sec. I, pp. 61-81 (The Macmillan Co., New York, N.Y., 1962).

The transport of heat through dielectric powders and dielectric-metallic powder mixtures is investigated theoretically and experimentally for temperatures below $300^{\circ} \mathrm{K}$. The most general formulation of the problem results in a non-linear integro-differential equation that is not solvable in closed form however, a much simpler formulation is made for evacuated powders that allows certain qualitative conclusions. An attempt is made to separate out the radiative and solid heat conduction. Experimental procedures and results are reviewed.

Reference tables for $40 \%$ iridium-60\% rhodium versus iridium thermocouples, G. F. Blackburn and F. R. Caldwell, Book, Temperature, Its Measurement and Control in Science and Industry 3, Pt. 2, 161-175 (Reinhold Publ. Corp., New York, N.Y., 1962).

In a program to establish reference tables for several alloys of iridium and rhodium against iridium, the work has been completed on $40 \%$ iridium- $60 \%$ rhodium. Tables have been prepared giving emfs for temperatures in degrees Fahrenheit from $32^{\circ} \mathrm{F}$ to $3800^{\circ} \mathrm{F}$ and in degrees Celsius (centigrade) from $0^{\circ} \mathrm{C}$ to $2100^{\circ} \mathrm{C}$, and temperatures in these units with emf in millivolts as the argument. They are based on the average emfs measured on eight thermocouples, made from three lots of wire obtained in 1955,1958 , and 1960 .

Measurements at temperatures $32^{\circ} \mathrm{F}$ to $2500^{\circ} \mathrm{F}$ were made in a platinum-wound furnace of conventional design, using a Pt-10\% Rh vs Pt thermocouple to measure temperature. From $1950^{\circ} \mathrm{F}$ to $3800^{\circ} \mathrm{F}$ (thus overlapping the upper end of the lower range), the furnace used was an iridium block heated by electric induction. Blackbody conditions prevailed in the cavity in which the test thermocouple was inserted, and enabled measurement of the temperature with an optical pyrometer
The cement reference laboratory (1929-1959), J. R. Dise, Am. Soc. Testing Materials Proc. 59, 369 (1959).

Recent changes in the scope of its operations have stimulated numerous inquiries about the functions of the Cement Reference Laboratory. Therefore, as a record which may be of special interest to those engaged in the testing of cements and concretes, and of general interest to those engaged in the testing of other materials, a report has been prepared which covers the origin, purpose, and development of each of the present responsibilities of the Reference Laboratory.

International coordination of measurement, A. G. MeNish, Sci. Math. Weekly 2, No. 3, 28-29 and 35 (Sept. 1961).

International coordination of measurement standards permits scientists in one country to relate their measurements to those made by scientists in another country. Such coordination is provided by the International Bureau of Weights and Measures and the General Conference on Weights and Measures. In October 1960 the Conference redefined the meter in terms of a wavelength of light from krypton 86 . Efforts are now being made to arrive at an atomic definition of the second.

The calibration at the National Bureau of Standards of mass standards for ultramicroanalysis, L. B. Macurdy, Book, Vacuum Microbalance Techniques, ed. R. F. Walker, 2, 165175 (Plenum Press, Inc., New York, N.Y., 1962).

Measurements may be made with a precision of tenths or hundredths of a microgram. Small weights suffer from an unfavorable surface to mass ratio and should be checked from time to time. This may be done by the regular procedures used in weight calibration, provided a suitable selection of nominal weight values exist in each set.

Post office mechanization, B. M. Levin, M. C. Stark, and P. C. Tosini, Elec. Eng. 80, No. 2, 105-110 (Feb. 1961.)

The introduction of mechanical equipment into the Post Office for the sorting and handling of mail makes feasible the development of procedures for maintaining precise data regarding the status of mail being sorted. These are the data needed by a computer that would regulate the flow of mail throughout the sorting process. Such a computer would control the flow of mail on conveyor belts, would make decisions regarding the type of sorting done by each sorting machine and would change these decisions when conditions warrant. The introduction of such a computer should improve service and reduce costs.

Rate of vaporization of refractory substances, J. J. Diamond, J. Efimenko, R. F. Hampson, and R. F. Walker, (Proc. 4th Intern. Symp. Reactivity of Solids), Book, Reactivity of Solids, ed. J. H. de Bower, et al., p. 725 (Elsevier Publ. Co., Amsterdam, The Netherlands, 1961).

The more important factors affecting the rate of vaporization of solid systems are summarized. Techniques for measuring the rates of vaporization of refractory substances at temperatures in the $1600-3000^{\circ} \mathrm{C}$ range are briefly described. The techniques pertain to measurements both in vacuum and in the presence of foreign gases. Some of the factors and the experimental techniques are illustrated by brief reference to studies of the vaporization of platinum and aluminum oxide.

A nomograph for selecting light balancing filters for camera exposure of color films, C. S. MeCamy, Med. Biol. Illustration, London, England 11, No. 1, 13-15 (Jan. 1961).

A nomograph is given for rapid selection of filters for color photography. The nomograph provides for a very large number of combinations of films and light sources in a simple form, permits the easy interpolation of new films, light sources, or filters, indicates which filters would be most nearly satisfactory when an ideal filter is not available, indicates the general nature of abnormal combinations for special effects, and provides a convenient conversion from color temperature to reciprocal color temperature. The nomograph is based on the assumption that the color balance of color films, the chromaticity of the illumination, and the effect of filters can be characterized adequately on a scale of reciprocal color temperature and that the change of reciprocal color temperature by a given filter is a constant. 
Young's modulus of single crystal corundum form $77{ }^{\circ} \mathrm{K}$ to $850^{\circ}$ K, J. B. Wachtman, Jr., W. E. Tefft, and D. G. Lam, Jr., Book, Mechanical Properties of Engineering Ceramics, $p$. 221-223 (Interscience Publ. Inc., New York, N.Y., 1961)

An equation is proposed to represent the temperature dependence of Young's modulus. This equation fits data on some corundum single crystals very well.

A controller for maintaining a constant rate of vaporization in fractional distillation, E. C. Kuehner and R. T. Leslie, Anal. Chem. 34, No. 9, 1155-1156 (Aug. 1962.)

A controller for maintaining a constant rate of vaporization from the pot of a fractionating column is described. To show the performance of the controller, a comparison is made of the constancy in efficiency of a still during controlled and uncontrolled test runs.

A method for determing mechanical resonance frequencies and for calculating elastic moduli from these frequencies, S. Spinner and W. E. Tefft, Am. Soc. Testing Materials Proc. 61, 1221-1238 (1961).

Part I describes the techniques for exciting, detecting, and measuring the mechanical resonance frequencies of specimens. These resonance frequencies have many useful diagnostic applications (for quality control, for instance) even when the elastic moduli are not calculated from them. Part II describes the methods for calculating the various elastic moduli from the appropriate resonance frequencies.

The dynamic compressibility of a rubber-sulfur vulcanizate and its relation to free volume, J. E. McKinney, H. V. Belcher, and R. S. Marvin, Trans. Soc. Rheology 4, 347-362 (1960).

The dynamic bulk compliance of natural rubber-12 sulfur was measured for varying static pressure (0 to 1000 bar), temperature $\left(-30\right.$ to $\left.+70^{\circ} \mathrm{C}\right)$, and frequency (50 to 1000 cps). The data can be represented by reduced frequency or temperature plots, assuming viscosity is proportional to exp $(1 /)$, a fractional free volume which is a linear function of temperature and pressure. The temperature-frequency reduction fits the "universal" WLF constants, and the temperature-pressure reduction term is practically the same as that found by Singh and Nolle for polyisobutylene.

Suggested arrangement of mirrors to form multiple reference angles, J. B. Saunders, J. Opt. Soc. Am. 51, No. 8, 859-862 (Aug. 1961).

A reference angle is described that forms, by successive or multiple reflections, a multiplicity of equal optical angles having common vertices. This angle may be used as a standard for calibrating circular scales either with an autocollimator or an interferometer. The angle can be adjusted in an interferometer to a very high accuracy. If the faces of the mirrors are 6 inches long, an error of 0.1 fringe corresponds to an error in the angle of 0.02 second of arc.

D-C differential current meter, E. Niesen, Rev. Sci. Instr. 32, No. 12, 1407-1408 (Dec. 1961).

A technique is described using a commercial clip-on d-c milliammeter to make sensitive differential current measurements.

High-energy X-ray spectrometer using large anticoincidence sodium iodide crystals, J. M. Wycoff, Proc. Total Absorption Gamma-Ray Spectrometry Symp., Gatlinburg, Tenn., May 10, 1960, p. 201-210 (1960)

A 9-in.-dia by 6.25-in.-long erystal has been used in a total absorption spectrometer for X-rays in the 5- to $100-\mathrm{Mev}$ range. The well-collimated X-rays are directed onto the side and along a diameter of the main crystal. On the exit side, a $6.75 \times 3.63$ in. NaI crystal has been set in anticoincidence to detect radiations above $0.6 \mathrm{Mev}$. The combination of the large crystal and the anticoincidence crystal has improved considerably the resolution for high-energy X-rays over the resolutions obtained with various combinations of crystals that were summed to provide a total absorption pulse. The final test of the resolution (and detailed response function shape) will come from activation curve and $(p, \gamma)$ data. The initial indications of the improved resolution will be demonstrated by the comparison of the shapes of pulse-height dis- tributions produced by $90-\mathrm{Mev}$ bremsstrahlung spectra transmitted by a $604-\mathrm{cm}$ water attenuator. This spectrum has a characteristic dip at $22 \mathrm{Mev}$ due to giant resonance nuclear absorption which required good resolution for its detailed observation.

Determination of the dissociation equilibria of water by a conductance method, H. C. Duecker and W. Haller, J. Phys. Chem. 66, No. 2, 225-229 (Feb. 1962).

Electrical conductivity measurements have been made at various temperatures on electrophoretically purified water with varying impurity content. The temperature coefficients of conduction are determined at 18 and $25^{\circ} \mathrm{C}$ for each fraction. An expression is derived for the activation energy of conduction of dilute aqueous solutions as a function of electrical conductivity. Upon substitution of the calculated activation energies of conduction into this expression, the theoretical conductivity of pure water is calculated to be $.0373 \times 10^{-6} \mathrm{ohm}^{-1} \mathrm{~cm}^{-1}$ at $18^{\circ}$, a volume $3 \%$ lower than predicted by Kohlrausch sixty years ago. The dissociation constants for water calculated from this value, the equivalent conductance of the ions and the density, however, agree with those determined from the E.M.F. of galvanic cells.

The rapid selector and other NBS document retrieval studies, J. L. Pike and T. C. Bagg, Proc. National Microfilm Assoc. Annual Meeting, Wash. D.C., A pr. 25-27, 1962, XI, 213-227 (Annapolis, Md., 1962).

Rapid Selectors are electro-mechanical devices for reproducing selected frames from reels of coded microfilm.

A brief history of the Rapid Selector development and a description of the various models is given.

Several other document retrieval problems studied at the National Bureau of Standards are described.

Determination of oxidation rates of air-blown asphalts by infrared spectroscopy, J. R. Wright and P. G. Campbell, J. Appl. Chem. 12, 256-266 (June 1962).

Oxidation rates for eight air-blown asphalts were determined by measuring the change in infrared absorption at $5.88 \mathrm{mi}-$ crons with time of exposure to the radiant energy of a carbonarc. While all the asphalts oxidized at different rates, those from the same geographical areas had similar rates; those from different areas varied considerably. The pattern of oxidation was generally the same for each of the eight asphalts, in that there was an induction period followed by a steady oxidation rate until near the failure point, beyond which time the oxidation rate accelerated until film failure as denoted by asphalt film cracking. An inverse relationship was found between the rate of oxidation and the accelerated weathering durability of each asphalt.

Thermocouple materials, F. R. Caldwell, Book, Temperature Its Measurement and Control in Science and Industry 3, Pt. 2, 81-134 (Reinhold Publ., Corp. New York, N.Y., 1962).

Thermocouple materials are considered that are used primarily as immersion temperature sensors in the range from $0^{\circ} \mathrm{C}$ up. Included are the conventional thermocouples that have survived since the beginnings of the art of thermoelectric temperature measurement, newer noble metal thermocouples, and thermocouples of refractory metals for use in the extreme range for immersed sensors. Because of the wide use and increasing popularity of ceramic-packed thermocouples in metal sheaths, they are included.

Limitations of the thermocouple wires are given as to range, stability, environment included atmosphere, magnitude of thermoelectric emf, and accuracy of commercially available materials of standard and extra quality. In addition, properties of the separate elements that are pertinent to the selection or use of thermocouples have been compiled.

In the case of the ceramic-packed thermocouples the following properties are presented: temperature range of the sheath, mechanical properties of the sheath, kinds of packed insulation, resistance between thermocouple wires and between wires and sheath, minimum bending radius of the packed stock, gas-tightness of the packed insulation, and types of measuring junctions available, i.e., grounded, ungrounded, bare, totally enclosed, stagnation mounting, etc. 
An equation of state for calculating the thermodynamic properties of helium at low temperatures, R. D. McCarty and R. B. Stewart, Book, Progress in International Research on Thermodynamic and Transport Properties, $p p$. 10\%-117 (Academic Press, Inc., New York, N.Y., 1962).

A new equation of state for helium gas with six adjustable constants is presented. This relation is adequate for the representation of the P-V-T data and for the calculation of the entropy and enthalpy for a range of temperatures from 20 to $300^{\circ} \mathrm{K}$, with pressures to 100 atmospheres. A comparison of calculated volumes with the original data indicates an average arithmetic deviation of 0.07 percent and maximum deviations of 0.5 percent. A comparison of calculated pressures with original data indicates about the same average and maximum deviations. A temperature-entropy chart and a compressibility factor chart have been prepared from values calculated by this equation of state. Tabular values of density, enthalpy and entropy for even values of temperature and pressure are also included.

Thermal expansion of some engineering materials from $20^{\circ}$ $\mathbf{K}$ to $293^{\circ} \mathbf{K}$, V. Arp, J. H. Wilson, L. Winrich, and P. Sikora, Cryogenics 3, 230 (June 1962).

Tables are given of the thermal expansions of some materials of engineering interest. The measurements were made in the temperature range from $20^{\circ} \mathrm{K}$ to $293^{\circ} \mathrm{K}$.

Interlaboratory evaluation of a method for indicated brightness of papers containing fluorescent brighteners, T. W Lashof and J. M. Patek, Tappi 45, No. 7, 566 (July 1962). A proposed modification of the method developed by Grum and Wightman for measuring indicated brightness of papers containing fluorescent brighteners was investigated using the proposed Tappi Recommended Practice for Interlaboratory Evaluation of Test Methods. The replication error was found to be negligible compared with other sources of variability, and therefore, from a precision viewpoint, it would be wasteful to make more than one measurement on a sample unless these other sources of variability are reduced. The usefulness of the proposed method was found to be limited by the high between-laboratory variability and the relatively high random interaction, both of which may have been caused by improper lamp calibration. The high between-laboratory variability may also have been due to improper preparation and use of the $\mathrm{MgO}$ standards. It is believed that these elements, and therefore the precision and usefulness of the method, may be improved without much difficulty.

An intermediate size automatically controlled hydrogen refrigeration system, D. B. Chelton, D. B. Mann, and B. W Birmingham, Suppl. Bull. Inst. Intern du Froid, Eindhoven, Comm. 1, Annexe 1960-61, 169-178 (1969).

Increasing interest in cryogenic systems operating in the temperature range $21^{\circ}$ to $30^{\circ} \mathrm{K}$ has created a need for a simple and reliable hydrogen refrigeration system. Such a refrigeration system, developed for use with a large liquid hydrogen bubble chamber, is described. The refrigerator has a maximum capacity of 4 kilowatts at temperatures between $21^{\circ} \mathrm{K}$ and $30^{\circ} \mathrm{K}$. Control is automatic and is of high sensitivity. Refrigeration may be provided at either a single zone (heat source) or multizones with temperature control of each zone.

Efficient operation of the refrigeration system depends on high performance heat exchangers. Methods used to design the heat exchangers are described. Generalized design charts which make possible the design of larger capacity systems of the same general type can be developed.

Thermal radiation standards and measurements of the Radiometry Section at the National Bureau of Standards, A. G Maki, (Proc. Conf. Radiative Transfer from Solid Materials, Boston, Mass., Dec. 12-13, 1960), Book, Radiative Transfer from Solid Materials, ed. H. H. Blau, Jr., and H. Fischer, Sec. II I, p. 135-141 (The Macmillian Co., New York, N.Y., 1962). A discussion was given of two aspects of the work of the Radiometry Section at the National Bureau of Standards. Two standards of thermal radiation were described and the method of their calibration detailed. The latter half of this paper will include a description of some work currently being carried on with the aim of obtaining the normal spectral emissivity of gold, aluminum, and platinum in the infrared.

Absolute microwave refractometer, M. J. Vetter and M. C. Thompson, Jr., Rev. Sci. Instr. 33, 656-660 (June 1962).

A simple microwave refractometer has been developed using a null technique which has considerably reduced drift and other instabilities introduced by the electronic components, including the klystron. The long-term stability indicates the justification for more fundamental calibration techniques which are described. The result is an instrument in which cavity stability rather than electronic stability is the limiting factor.

Ferroelectricity in the compound $\mathrm{Ba}_{2} \mathbf{B i}_{4} \mathbf{T i}_{5} \mathbf{O}_{18}$, P. H. Fang and B. Aurivillius, Phys. Rev. 126, No. 3, 893 (May 1962). Some ferroelectric and crystallographical properties of the compound $\mathrm{Ba}_{2} \mathrm{Bi}_{4} \mathrm{Ti}_{5} \mathrm{O}_{18}$ are presented. The compound represents a new structure with the unit cell consisting of one $\mathrm{Bi}_{2} \mathrm{O}_{2}{ }^{2+}$ layers. From $196^{\circ} \mathrm{C}$ to $580^{\circ} \mathrm{C}$, a maximum in the real part of the dielectric constant was observed at $+417^{\circ} \mathrm{C}$. No thermal hysteresis was observed within the precission of $12^{\circ} \mathrm{C}$. A remanent paralization of $2 \times 10^{-6} \mathrm{coul} / \mathrm{cm}^{2}$ and a coercive field of $10 \mathrm{kv} / \mathrm{cm}$ were observed at the room temperatures.

The ammonia beam maser as a standard of frequency, J. A. Barnes, D. W. Allan, and A. E. Wainwright, IRE Trans. Instrumentation I-11, 26-30 (June 1962).

It has been suggested that an error in tuning of the resonant cavity in an ammonia beam maser could be detected by observing a frequency shift of the maser with the application of a magnetic field Following this suggestion, an ocsillatory magnetic field was applied to the NBS double beam maser and a low noise phase demodulator was constructed to detect any phase modulation present in the maser signal. With this equipment, a servo-loop was completed to constantly control the tuning of the maser's resonant cavity. Not only did this result in the elimination of the most critical parameter of the maser's frequency dependence, but improvement of the frequency dependence upon other parameters was also observed.

Large longitudinal retarded elastic deformation of rubberlike network polymers, H. Leaderman, J. Polymer Sci. 59, No. 168, S42 (June 1962).

Measurements of longitudinal creep under constant nominal tensile stress and of recovery, and also of creep under constant true tensile stress and recovery have been made on a specimen of plasticized polyvinyl chloride. These data have been shown to be consistent with linear superposition relations of the hereditary type. Associated with nominal stress as excitation is $\left(\lambda-\lambda^{-2}\right) / 3$ as the measure of response, where $\lambda$ is relative length. Associated with true stress as excitation is $\left(\lambda^{2}-\lambda^{-1}\right)\left(1+0.8 \lambda^{-1}\right) / 5.4$ as the measure of response.

Magnifications of a telescope, R. E. Stephens, J. Opt. Soc. Am. 51, No. \%, 803-804 (July 1961).

The image of a distant object formed by a telescope appears larger than the object in spite of the fact that the linear dimensions are reduced in size. This is becalse the image is always much nearer the observer than the object. The ratio of the image distance to the object distance approaches $1 / \mathrm{M}^{2}$ as both distances approach infinity, where $M$ is the angular magnification of the telescope.

Linear thermal expansion of aluminum oxide and thorium oxide from $100^{\circ}$ to $1100^{\circ} \mathrm{K}, \mathrm{J}$. B. Wachtman, Jr., T. G. Scuderi, and G. W. Cleek, J. Am. Ceram. Soc. 45, 310-323 (July 1962).

The linear thermal expansion of single erystal and polycrystalline aluminum oxide and polycrystalline thorium oxide was measured trom $100^{\circ}$ to $1100^{\circ} \mathrm{K}$ with an interferometric technique. For each substance the results are well described by Grüneisen's equation using a Nernst-Lindemann energy function.

Group theory and crystal field theory, C. M. Herzfeld and P. H. E. Meijer, Book, Solid State Physics 12, 1-19 (Academic Press, Inc., New York, N.Y., 1961). 
A survey of the principal group theoretical principles and methods used in crystal field theory.

Ferroelectricity in the compound $\mathbf{B i}_{4} \mathbf{T i}_{3} \mathbf{O}_{12}, \mathrm{P}$. H. Fang and C. R. Robbins, Phys. Rev. 126, No. 3, 892 (May 1962).

Some ferroelectric and crystallographical properties of the compound $\mathrm{Bi}_{4} \mathrm{Ti}_{3} \mathrm{O}_{12}$ are presented. The compound has a dielectric maximum at $685^{\circ} \mathrm{C}$ on increasing temperature and at $670^{\circ} \mathrm{C}$ on decreasing temperature. At these temperatures, an endothermic peak and an exothermic peak, respectively, occur. Ferroelectricity was observed along the $c$ axis of the single crystal of this compound.

Blue-glass filters to approximate the blackbody at $6500^{\circ} \mathrm{K}$, D. B. Judd, Farbe 10, No. 1-4, 31 (1961).

In 1956, Rautian, Lobanova, and Znamenskaya described a light source for precise color measurement of non-selfluminous objects with an energy distribution between 400 and $700 \mathrm{~nm}$ closely duplicating that of a blackbody at $6,500^{\circ} \mathrm{K}$. This light source took the form of an incandescent lamp at a color temperature of $2,854^{\circ} \mathrm{K}$ (CIE source A) combined with a three-layer, blue-glass, filter of the Ronis type An attempt in February 1959 to purchase such Ronis filters indicated that they were not yet commercially available. At the request of the National Bureau of Standards, Corning Glass Works undertook the design and production of such a filter under the direction of their A. J. Werner, and in December 1960 delivered a supply of them. Measurements show that the degree of duplication of the blackbody energy distribution for $6,500^{\circ} \mathrm{K}$ available from the Corning three-laver filter is slightly better than that reported for Ronis-type filters.

Application of reflectometer techniques to accurate reflection measurements in coaxial systems, R. W. Beatty and W. J. Anson, Proc. Inst. Elec. Engr. B109, 345-348 (July 1962).

The theory of a single directional coupler reflectometer having two auxiliary tuners is reviewed, giving emphasis to precision measurement possibilities.

Problems in setting up this system for measurements in coaxial line are discussed and a system for measurements in the frequency range $3.95-5.85 \mathrm{Gc} / \mathrm{s}$ is described.

The development of quarter wavelength short-circuit reflection standards and sliding terminations is presented.

The results of measurements of the reflection from connectors and various loads at $4 \mathrm{Gc} / \mathrm{s}$ are given.

Four methods for predicting the durability of roofing asphalts, S. H. Greenfeld and J. R. Wright, Mater. Res. Std. 2, No. 9, 738-745 (Sept. 1962).

Four laboratory procedures (asphaltene content, filtration time, solubility parameter, and carbonyl index) for predicting the durability of 24 coating-grade roofing asphalts as determined in accelerated-weathering machines were studied. Durability tended to vary directly with filtration time, and inversely with solubility parameter, asphaltene content, and carbonyl index. There was scatter in the data in all of the correlations, but the asphalts tended to be grouped according to the so'rrce of the crudes from which they were obtained. Modifications to the asphalts produced by additives, fluxing oils, and blending stocks tended to make the asphalts deviate from their source groups.

Coring an electroform, W. H. Metzer, Jr., Plating 49, No. 8, 880 (Aug. 1962).

Article describes novel method for removing soluble mandrels from thin walled electroforms. The electroformed part containing the mandrel is sealed, together with a reagent, in a closed system which is heated in a furnace. Mandrels have been removed from electroformed shells by this method where no ordinary means would work.

Four-place table decibels return loss to magnitude of voltage reflection coefficient, $\mathrm{R}$. W. Beatty, Microwave Eng. Handb. \& Buyers Guide, p. TD188-192 (Nov. 1961).

A four place table of the magnitude of $|\Gamma|$ of the voltage reflection coefficient corresponding to the return loss $\mathrm{L}_{\mathrm{R}}=20$ $\log _{10} \frac{1}{|\Gamma|}$ is given. $\mathrm{L}_{\mathrm{R}}$ is given to 0.01 decibel intervals over the range 0-20 decibels. A simple procedure permits use of the table outside of this range.
Insulation resistance measurements, A. H. Scott, Proc, 4th Electrical Insulation Conf., Materials and Application, Wash., D.C., pp. 115-117 (Feb. 19-22, 1962).

Some comments are made regarding the reasons for interest in electrical insulation-resistance measurements. A brief review of the advantages, disadvantages and sensitivity is given for various types of equipment used for making electrical insulation measurements. Also some pitfalls in making insulation measurements are mentioned. A short reference to electrode materials which can be used is given. This discussion is intended to give a background for the open discussion on Measurement of Insulation Resistances Greater than 1016 ohms, which will form the last part of the session.

Some tensile properties of amalgam, M. S. Rodriguez and G. Dickson, J. Dental Res. 41, No. 4, 840-852 (July-Aug. 1962).

Methods were developed for measuring the tensile properties of dental amalgam. Specimens used were dumbbell shaped with a straight portion of 0.01 in. $^{2}$ cross section and approximately $0.30 \mathrm{in}$. length. Tensile strengths of four amalgams ranged from approximately 7000 to 8500 psi. Elongations calculated over a 0.5 in. gage length varied from 0.3 to $0.5 \%$ Chord moduli of elasticity from stresses of 1000 to 3000 psi for specimens of the four amalgams strained at a rate of 0.003 in. per minute averaged $3.3-4.1 \times 10^{6}$ psi and from 1000 to 5000 psi averaged $2.2-2.8 \times 10^{6}$ psi.

A study of the chemical and physical properties of magnetic recording tape, F. Nesh and $\mathrm{R}$. F. Brown, Jr., IRE Trans. Audio AU-10, No. 3, 70-71 (May-June, 1962).

A study has been made of the chemical and physical properties of magnetic recording tape. The chemical studies indicate the possible relationship between a series of solvent tests and the wear properties of commercially available tapes. The physical studies, including electron micrographs indicate a smaller unit crystal size for $\gamma$ Ferric Oxide than previously supposed and a relationship between a better dispersion and improved magnetic properties. Both studies are being continued in greater detail.

Measurement of effect of moisture on heat transfer through insulated flat-roof constructions, F. J. Powell and H. E. Robinson, Am. Soc. Testing Materials Spec. Tech. Publ. 312, 35-66 (1951).

Two methods of measurement are presented for laboratory determination of the effect of moisture on the heat transfer through insulated flat-roof constructions when subjected to successive periods of simulated summer and winter temperature conditions, and daily solar heating of the top surface. The methods allow simultaneous measurements to be made on specimens of different designs. Heat-flow meters are used in the first method and a calorimeter technique in the second for observing changes in the insulating value of the entire construction and its components due to moisture. The second method includes a means for measuring the rate of change of moisture content of the specimen.

Illustrative results are given for thirteen of the fifty-four specimens tested over a period of five years. Results indicate that natural in-place drying of wetted insulation over a vapor barrier and/or a dense concrete deck is very slow, and that once wetted, such insulation will have greater heat transmission for long periods of time. Some constructions made without vapor barriers, containing materials of moderate permeance, showed good drying characteristics, so that if initially wet, or wetted later, the insulation approached dryness in a period comparable to a year's service.

APPA-TAPPI reference material program, I. Interlaboratory investigation of TAPPI standard T $414 m-49$, internal tearing resistance of paper, T. W. Lashof, Tappi $\mathbf{4 5}$, No. 8, 656 (1962). The initial stens in a project to improve the reproducibility of this long established method of test are presented. These included (1) refinement of the procedure based on information that had been accumulated in the literature and by the manufacturer of the testing instrument and others over the years, and (2) an interlaboratory study involving 40 laboratories and 8 materials covering the range of the method. A withinlaboratory replication error of $5.3 \%$ coefficient of variation was found. The present TAPPI standard calls for at least 
5 replications, but the analysis shows that as many as 10 replications would still be useful, provided that differences between laboratories are adjusted using a standard sample. Between-laboratory variability is so large that even when only 5 replications are used to reduce the effect of withinlaboratory variability, a standard sample will significantly reduce between-laboratory variability.

Properties of dental amalgams made from spherical alloy particles, N. C. Demaree and D. F. Taylor, J. Dental Res. 41, No. 4, 890-906 (July-Aug. 1962).

Experimental dental amalgams were prepared for the first time from a tycical amalgam alloy ( $\mathrm{Ag} 70.6 \%$, Sn $26.1 \%, \mathrm{Cu}$ $2.5 \%, \mathrm{Zn} 0.4 \%$ ) in the form of spherical particles 2 to 150 microns in diameter rather than in the irregular particles normally employed. Properties of amalgams made, using particles of 8 size ranges, were investigated. Dimensional change on setting and setting time were greater but residual mercury content was lower for amalgam made from the larger particles. Particles between 15 and 50 microns in diameter gave maximum strength. Physical properties of some of the experimental amalgams were equal or superior to properties of dental amalgams now in use. The use of spherical particles provides a new approach to the investigation of the setting reactions of dental amalgam.

Fast-melting alloy forms water jacket for small klystrons, W. J. Anson and E. Niesen, Electron. Design, pp. 42-45 (Mar. 1962).

Many klystrons radiate strong external signals and often require good shelding in laboratory setups to eliminate interference between the r.f. source and the detection system. This article describes some simple approaches to both the shielding and the cooling problems.

\section{Other NBS Publications}

Journal of Research 66A (Phys. and Chem.), No. 6 (Nov.Dec. 1962), 70 cents.

Heat of formation of nitronium perchlorate. A. A. Gilliland.

Phase equilibrium relations in the binary system bismuth sesquioxide-niobium pentoxide. R. S. Roth and J. L. Waring.

Elastic constants of rutile $\left(\mathrm{TiO}_{2}\right)$. J. B. Wachtman, Jr., W. E. Tefft, and D. G. Lam, Jr. (See above abstracts.)

Reaction of hardened portland cement paste with carbon dioxide. C. M. Hunt and L. A. Tomes. (See above abstracts.)

Titanium standards for hydrogen content. J. T. Sterling, F. J. Palumbo, and L. L. Wyman.

Ul rsviolet stability of crosslinked polycaprolactam systems. S. D. Bruck.

spectral-line intensities and $g f$-values in the first spectrum of copper. C. H. Corliss.

Batch adsorption from solution. W. V. Loebenstem.

Separation of hafnium from zirconium and their determination: Separation by anion-exchange. L. A. Machlan and J. L. Hague.

Journal of Research 66B (Math. and Math. Phys.), No. 6 (Oct.-Dec. 1962), 75 cents.

Reliability of a system in which spare parts deteriorate in storage. G. H. Weiss. (See above abstracts.)

Estimation of dispersion parameters. W. A. Thompson, Jr.

Laguerre expansions for successive generations of a renewal process. G. H. Weiss.

Bounds on ratios of means. G. T. Cargo and O. Shisha.

A model for the viscoelastic behavior of rubberlike polymers including entanglement effects. R. S. Marvin and $H$. Oser. (See above abstracts.)

Black box maximization of circular coverage. C. T. Zahn, Jr.

An application of information theory to the analysis of contingency tables, with a table of $2 n 1 n n, n=1(1) 10,000$. S. Kullback, M. Kupperman, and H. H. Ku.

\section{Journal of Research 66D (Radio Prop.), No. 6 (Nov.-Dec.} 1962), 70 cents.

RF impedance probe measurements of ionospheric electron densities. J. A. Kane, J. E. Jackson, and H. A. Whale. (See above abstracts.)
Methods for applying numerical maps of ionospheric characteristics. W. B. Jones and R. M. Gallet.

Very-low-frequency radio propagation in the ionosphere. D. W. Swift.

Prolonged space-wave fadeouts in tropospheric propagation. A. P. Barsis and M. E. Johnson.

Range-error compensation for a troposphere with exponentially varying refractivity. J. J. Freeman.

On the geometrical optics of curved surfaces with periodic impedance properties. C. J. Marcinkowski and L. B. Felsen. (See above abstracts.)

On the limitations of geometrical optics solutions for curved surfaces with variable impedance properties. C. J. Marcinkowski and L. B. Felsen. (See above abstracts.)

Conversion of the amplitude-probability distribution function for atmospheric radio noise from one bandwidth to another. A. D. Spaulding, C. J. Roubique, and W. Q. Crichlow.

Some statistical properties of pulsed oblique HF ionospheric transmissions. M. Balser and W. B. Smith.

Induction in a small loop moving with a magnetostatic dipole toward a conducting half space. M. B. Kraichman.

Propagation of terrestrial radio waves of long wavelengththeory of zonal harmonics with improved summation techniques. J. R. Johler and L. A. Berry.

Terminal-zone corrections for a dipole driven by a two-wire line. K. Iizuka and R. W. P. King.

Pattern synthesis with a flush-mounted leaky-wave antenna on a conducting circular cylinder. A. Ishimaru and F. R. Beich.

Analysis of electric energy usage in Air Force houses equipped with air-to-air heat pumps, P. R. Achenbach, J. C. Davis, and W. T. Smith, NBS Mono. 51 (July 13, 1962) 30 cents.

Annotated bibliography on soft $\mathrm{X}$-ray spectroscopy, $\mathrm{H}$. Yakowitz and J. R. Cuthill, NBS Mono. 52 (June 29, 1962) $\$ 1.00$.

Experimental transition probabilities for spectral lines of seventy elements, C. H. Corliss and W. R. Bozman, NBS Mono. 53 (July 20, 1962) $\$ 4.25$.

Weights and measures administration, NBS Handb. 82 (June 22, 1962) \$1.75. (Supersedes H26)

Required signal-to-noise ratios, RF signal power, and bandwidth for multichannel radio communications systems, E. F. Florman and J. J. Tary, NBS Tech. Note 100 (Jan. $1962), \$ 1.00$.

Mode conversion in the earth-jonosphere waveguide, J. R. Wait, NBS Tech. Note 151 (June 8, 1962) 20 cents.

Information selection systems retrieving replica copies: A state-of-the-art report, T. C. Bagg and M. E. Stevens, NBS Tech. Note 157 (Dec. 31, 1961) \$1.25.

Efficient use of the radio spectrum, K. A. Norton, NBS Tech. Note 158 (Apr. 1962) 45 cents.

A Fortran code for calculation of eigenvalues and eigenfunctions in real potential wells, R. S. Caswell, NBS Tech. Note 159 (Aug. 1962) 25 cents.

Propagation of solar particles and the interplanetary magnetic field, C. S. Warwick, J. Geophys. Research 67, No. 4, 13331346 (Apr. 1962).

Availability of machine-usable natural language material, M. E. Stevens, Proc. 3d Inst. on Information, Storage and Retrieval (American Univ., Wash., D.C.), 1, 58-75 (Feb. 1961).

Physical measurements and experiment design, W. J. Youden, Le Plan d'Exper. Centre Natl. Recherche Sci. (Paris, France) 110, 1-13 (Aug.-Sept. 1961).

A calculus for factorial arrangements, B. Kurkjian and M. Zelen, Annals. of Math. Statistics 33, 600-619 (June 1962).

Modular forms whose coefficients possess multiplicative properties (II), M. Newman, Ann. of Math. 75, 242-250 (Mar. 1962)

Transition probabilities for permitted and forbidden lines of Si X, Fe XIV and Fe X, R. H. Garstang, Extrait des Ann. d'Astrophys. 25, No. 2, 109-117 (1962).

A note on normal matrices, M. Marcus and N. Khan, Can. Math. Bull. 4, 23-27 (1961).

The evolution of concepts and languages of computing, R. D. 
Elbourn and W. H. Ware, Proc. IRE 50, No. 5, 1059-1066 (May 1962).

National Bureau of Standards list of IGY flares with normalized values of importance and area, C. S. Warwick, IGY Solar Activity Report Series No. 17 (Intern. Geophys. Year, World Data Center A. Solar Activity, High Altitude Observatory, University of Colorado, Boulder, Colorado, May 1, 1962).

Plural scattering of 20-kev electrons in aluminum, L. Marton, J. A. Simpson, H. A. Fowler, and N. Swanson, Phys. Rev. 126, No. 1, 182-192 (Apr. 1, 1962)

Time and its inverse, J. M. Richardson, Intern. Sci. and Tech. 1, No. 6, 54-61 (June 1962).

Effect of crystal growth on the comparative fixation of $\mathrm{Sr}^{89}$ and $\mathrm{Ca}^{45}$ by calcified tissues, R. C. Likins, A. S. Posner, B. Paretzkin, A. P. Frost, J. Biol. Chem. 236, 2804-2806 (Oct. 1961).

Introduction, H. S. Peiser, Book, Vacuum Microbalance Techniques, Ed. R. F. Walker, 2, 1-5 (Plenum Press, Inc., New York, N.Y., 1962).

The effect of geomagnetic activity on the $F_{2}$ region over central Africa, R. G. Rastogi, J. Geophys. Research 67, No. 4, 1367-1374 (Apr. 1962).

Growth rates of zinc erystals from the vapor phase, R. L. Parker and I. M. Kushner, J. Chem. Phys. 35, No. 4, 1345 (Oct. 1961).

Plastic standards in Government, F. W. Reinhart, Proc. Am. Standards Assoc. 12th Natl. Conf. Standards, pp. 44-46 (Houston, Texas, Oct. 1.961).

Anisotropies in angular distributions of molecular dissociation products, G. H. Dunn, Phys. Rev. 8, 62-64 (Jan. 15, 1962).

Heats of formation of inorganic fluorine compounds-A survey, G. T. Armstrong and L. A. Krieger, Progress on Intern. Research On Thermodynamics and Transport Properties, pp. 8-77 (ASME \& Academic Press, Inc., New York, N.Y., 1962).

Plastics, G. M. Kline, The Americana Annual, p. 603 (Americana Corp., Chicago, Ill., 1961)

Vibrational-rotational spectra of $\mathrm{BrCN}, \mathrm{A}$. G. Maki and C. T. Gott, J. Chem. Phys. 35, No. 9, 2282-2285 (1962).

Distribution of total service time for a fixed observation interval, W. S. Connor and N. C. Severo, J. Am. Stat. Assoc. 57, 376-386 (June 1962).

Abstract shape recognition by machine, M. E. Stevens, Computers - Key to Total Systems Control, Proc. Eastern Joint Computer Conf., 20, No. 1, 332-351 (Dec. 1961).

Determination of molecular weights and molecular weight distribution, D. MeIntyre, ASD Tech. Rept. 62-283, p. 71-74 (Mar. 1962).

Environmental chemistry, F. W. Reinhart, Prevention of Deterioration Center Newsletter (Natl. Acad. Sci.-Natl. Research Council) V, No. 1, 1-2, 4 (Oct. 1961).

A study of solar activity associated with polar-cap absorption, C. S. Warwick and M. W. Haurwitz, J. Geophys. Research 67, No. 4, 1317-1332 (Apr. 1962).

Stability of plastic impression trays, J. B. Woelfel and G. C. Paffenbarger, J. Am. Dental Assoc. 63, No. 5, 705-706 (Nov. 1961)

Electron spin resonance studies of $\gamma$-irradiated small molecules at $4{ }^{\circ} \mathrm{K}$ and $77^{\circ} \mathrm{K}, \mathrm{R}$. E. Florin, D. W. Brown and L. A. Wall, Proc. 5th Intern. Symp. on Free Radications, Paper No. 18, 1-17 (Almquist and Wiksell, Stockholm, Sweden, July 6-7, 1961).

Absolute isotopic abundance ratio and the atomic weight of chlorine, W. R. Shields, E. L. Garner and V. H. Dibeler, J. Am. Chem. Soc. 84, 1510-1522 (1962).

Departure from the steady state in two-intermediate enzyme reactions, H. Shin, Trans. Faraday Soc. 58, No. 475, 1439-1450 (July 1962).

Direct measurement of line intensities and widths in the first overtone band of $\mathrm{CO}, \mathrm{H}$. J. Kostkowski and A. M. Bass, J. Quant. Spectry. Radjative Transfer 1, 177-184 (1961).

Calibration of vibration pickups at large amplitudes, E. Jones, S. Edelman, and K. S. Sizemore, J. Acoust, Soc. Am. (Errata) 34, No. 3, 355 (Mar. 1962).

Dislocations and stacking faults in aluminum nitride, $\mathrm{P}$. Delavignette, H. B. Kirkpatrick and S. Amelinckx, J. Appl. Phys. 32, No. 6, 1098-1100 (June 1961).

Pair production as an analyzer of circular polarization of gamma rays from neutral particle decays, $H$. Olsen and
L. C. Maximon, Il Nuovo Cimento 24, No. 1, 186-189 (Apr. 1962).

Emission flame photometry, M. Margoshes, Anal. Chem. Suppl. 34, No. 5, 221R-224R (Apr. 1962).

Temperature dependent of electron emission in the field emmission region, R. Klein and L. B. Leder, Phys. Rev. 124, 1046-1049 (Nov. 1961).

Design requirements for mechanized systems in protective shelters, R. R. Achenbach, Heating, Piping and Air Conditioning 34, No. 2, 73-79 (Feb. 1962).

Spin-lattice relaxation in two rare earth double nitrates, R. P. Hudson and B. W. Mangum, Il Nuovo Cimento 23, 1133-1135 (Mar. 1962).

Dimensional changes in fibrous macromolecules: The system alpha-keratin-lithium bromide, L. Mandelkern, J. C. Halpin, A. F. Diorio and A. S. Posner, Am. Chem. Soc. 34, No. 8, 1383-1391 (Apr. 1962).

Tchebycheff approximation by functions unisolvent of variable degree, J. R. Rice, Trans. Am. Math. Soc. 99, 298-302 (1961)

Best approximations and interpolating functions, J. R. Rice, Trans. Am. Math. Soc. 101, 477-498 (Dec. 1961).

The presence of singly-ionized gallium (Ga II) lines in stellar spectra, W. P. Bidelman and C. H. Corliss, Astrophys. J. 135, No. 3, 968-969 (May 1962).

Theory and biomedical applications of the analog computers, H. L. Mason, Natl. Inst. of Health Workshop on Biomedical Computing, No. 1 (July 1961).

Universal-time control of the arctic and antarctic $F$ region, R. A. Duncan, J. Geophys. Research 67, 1823-1830 (May 1962).

Evaluation of the nature of the surfaces of hard tooth tissues by a surface activity test, R. L. Bowen, Proc. Workshop on Adhesive Restorative Dental Materials (Indiana Univ., Bloomington, Indiana, Sept. 28-29, 1961)

Liquid drop collisions, O. G. Engel, Symp. Erosion and Cavitation, Am. Soc. Testing Materials Spec. Tech. Publ. No. 307, 3-16 (1961).

On the determination of disintegration rates by the coincidence method using high efficiency detectors, R. W. Hayward, Intern. J. Appl. Radiation and Isotopes 12, 148-150 (Dec. 1961).

Field emission from niobium in the normal and superconducting states, R. Klein and L. B. Leder, Phys. Rev. 124, No. 4, 1050-1052 (Nov. 1961)

On the self-diffusion of ions in a polyelectrolyte solution, S. Lifson and J. L. Jackson, J. Chem. Phys. 36, No. 9, 2410-2414 (May 1962).

Mass spectrometry, R. M. Reese, Anal. Chem. 34, No. 5, 243R-254R (Apr. 1962).

Fifteen years ACM, F. L. Alt, Commun. Assoc. Computing Machinery 5, No. 6, 300-307 (June 1962).

Scattered radiation from large cobalt-60 calibrating sources, L. Costrell, Health Phys. J. 8, No. 3, 261-272 (June 1962).

Measurement characteristics of the farm milk tank, M. W. Jensen, J. Milk and Food Technol. 25, No. 4, 112-115 (Apr. 1962)

The microwave Zeeman effect of free hydroxyl radicals: ${ }_{2} \mathrm{II}_{1 / 2}$ levels, H. E. Radford, Phys. Rev. 126, 1035 (1962).

Effect of nonerystallizable components on the crystallization kinetics of polymers, F. Gornick and L. Mandelkern, J. Appl. Phys. 33, No. 3, 907-913 (Mar. 1962).

Standards for plasties in the U.S.A., G. M. Kline, Proc. 13th Intern. Plastics Congress, pp. 27-33 (Turin, Italy, Sept. $28-30,1961)$

Electron resonance magnetometer for alternating magnetic fields, O. E. Spokas and M. Danos, Rev. Sci. Instr. 33, No. 6, 613-617 (June 1962).

Traces of products of angular momentum matrices, I. Cartesian basis, E. Ambler, J. C. Eisenstein, and J. F. Schooley, J. Math. Phys. 3, No. 1, 118-130 (Jan.-Feb. 1962).

Measurement of linear photon polarization by pair production, L. C. Maximon and H. Olsen, Phys. Rev. 126, No. 1, 310-319 (Apr. 1962)

Standards for vinyl chloride plastics, F. W. Reinhart, Proc. SPE Regional Tech. Conf. "Vinyl Plastics" (New York, N.Y., Nov. 15, 1961) ; SPE J. 18, 308-311 (Mar. 1962).

Radiation hazards in realistic perspective, L. S. Taylor, Phys. Today 15, 32-38 (June 1962). 
The molecular structure of chloroform, M. Jen and D. R. Lide, Jr., J. Chem. Phys. 36, No. 9, 2525 (May 1962).

Device for chemically thinning crystals for transmission electron microscopy, H. B. Kirkpatrick and S. Amelinckx, Rev. Sci. Instr. 33, No. 4, 488-489 (Apr. 1962).

Signs of nuclear resonance coupling constants in saturated aliphatic systems, H. Finegold, Proc. Chem. Soc. (London, England), No. 6, pp. 213-214 (June 1962).

Collision-induced microwave absorption in compressed gases, II. Molecular electric quadrupole moments, G. Birnbaum and A. A. Maryott, J. Chem. Phys. 36, 2032-2036 (Apr. 1962)

Fluorescence in comets as a Markov process, T. Carrington, Astrophys, J. 135, No. 3, 883-891 (May 1962).

Digital pattern recognition by moments, F. L. Alt, J. Assoc. Computing Mach. 9, No. 2, 240-258 (Apr. 1962).

The nuclear photoeffect in holmium and erbium, E. G. Fuller and E. Hayward, Nuclear Phys. 30, 613-635 (1962).

Formation constant of the $1: 1$ pyridine-iodine complex, A. G. Maki and E. K. Plyler, J. Phys. Chem. 66, 766-767 (1962).

Photosensitized reaction between hydrogen $(2 p)$ atoms and molecular nitrogen, I. Tanaka and J. R. MeNesby, J. Chem. Phys. 36, No. $123170-3173$ (June 15, 1962).

Effect of particle size on low-temperature heat capacities, A. C. Victor, J. Chem. Phys. 36, No. 10, 2812-2813 (May $15,1962)$

Effect of molecular oxygen on the emission spectra of atomic oxygen-acetylene flames, S. L. N. G. Krishnamachari and H. P. Broida, J. Chem. Phvs. 34, 1709-1711 (1961)

Tchebycheff approximations by exponentials, J. R. Rice, J. Soc. Ind. Appl. Math. 10, No. 1, 149-161 (Mar. 1962).

The morphology of mid-latitude 6300 angstrom ares, T. Tohmatsu and F. E. Roach, J. Geophys. Res. 67, No. 5, 1817 1821 (May 1962)

Some electrical properties of the porous graphite contact on p-type silicon, G. G. Harman, T. H. Higier, and O. L. Meyer, J. Appl. Phys. 33, 2206 (July 1962).

The structure of the vibrational-rotational bands of an asymmetric rotor, H. C. Allen, Jr., Phil. Trans. Roy. Soc London, Ser. B. Math. and Phys. Sci. 253, No. 1030, 335 357 (Apr. 27, 1961)

Real representations of coordinate rotations, U. Fano, J Math. Phys. 1, No. 5, 417-423 (Sept.-Oct. 1960)

Structural and internal state variables in the description of scalar rate processes in fluids, R. E. Nettleton, Phvs. Fluids 4, 1488 (1961)

The types of blackout, their time variations, and the mechanisms producing them, V. Agy, J. Phys. Soc. Japan 17, 9397 (Sept. 1961)

Quantum-mechanical calculation of harmonic oscillator transition probabilities in a one-dimensional impulsive collision, K. E. Shuler and R. W. Zwanzig, J. Chem. Phys. 33, No. 6 , 1778-1784 (Dec. 1960)

The vapor pressure of $20{ }^{\circ} \mathrm{K}$ equilibrium hydrogen, L. C. Weber, Jr., D. E. Diller, H. M. Roder, and R. D. Goodwin, Cryogenics 3, 236-238 (June 1962).

Programming for a closed-loop manned-machine combined system, D. C. Friedman, Proc. Combined Analog Digital Computer Systems Symp., Phila., Pa., Dec. 1960, 12th item (1960)

Studies in non-equilibrium rate processes, V. The relaxation of moments derived from a master equation, K. E. Shuler, K. Anderson, and G. H. Weiss, J. Math. Phys. 3, No. 3, 550-556 (May-June 1962)

Kinetics of the hydroloysis of acetal in $\mathrm{N}$-methylpropionamide-water and $\mathrm{N}, n$-dimethylformamide-water solvents at 20, 25, 30, and $40^{\circ}, \mathrm{R}$. K. Wolford and R. G. Bates, J. Phys. Chem. 66, No.' 8, $1496-1500$ (1962).

Symposium on spectroscopic excitation, B. F. Scribner, Am Soc. Testing Materials Spec. Tech. Publ. 259, 1 (Oct. 1960).

Path loss measurements versus prediction for long distance tropospheric scatter circuits, A. F. Barghausen and C. F Peterson, IRE Trans, on Commun. Systems CS-9, No. 4 , 439-445 (Dec. 1961).

Introduction to the theory of V.L.F. propagation, J. R. Wait, Proc. IRE 50, 1624-1647 (July 1962),

Some experimental aspects of nuclear orientation, E. Ambler, Proc. Tenth Intern. Congress of Refrigeration, Copenhagen, Denmark, I, 195-198 (1959)
The densities of saturated liquid hydrogen, R. D. Goodwin, D. E. Diller, H. M. Roder, and L. A. Weber, Cryogenics ?, \$1-83 (Dec. 1961)

Irreversible processes in liquids and the density matrix: monatomic molecules, R. E. Nettleton, Phys. Fluids 5, No. 6, 687-700 (June 1962)

Swtiching properties in ferroelectrics of the family $\mathrm{Bi}_{4} \mathrm{Ba}_{m-2} \mathrm{Ti}_{m+1} \mathrm{O}_{3(m+2)}$, P. H. Fang and E. Fatuzzo, J. Phys. Soc. Japan 1\%, 238 (1962)

A derivation of the relaxation spectrum representation of the mechanical response function, R. S. Marvin, Repts. Progr. Polymer Phys. Japan 5, 56-58 (1962).

Thermal isomerization of isopropyl-1,1,1- $d_{3}$ radicals, W. M Jackson and J. R. MeNesby, J. Chem. Phys. 36, No. 9, 2272-2275 (May 1, 1962).

Research on light metals in the Metallurgy Division, National Bureau of Standards, T. G. Digges, (Symp. Light Metal Industry, Jamshedpur, India) Indian Construction News, p. 68 (Aug. 1961)

Attempts to eliminate fatigue damage by heat treatment, $J$ A. Bennett, Am. Soc. Metals, Trans. Quart. (Tech. Notes) 55, No. 2, 362-363 (June 1962).

Graphs for bivariate normal probabilities, M. Zelen and N. C. Servero, Ann. Math. Stat. 31, No. 3, 619-624 (Sept. 1960)

Nuclear moment of NI ${ }^{61}$, L. H. Bennett and R. L. Streever, Jr., Phys. Rev. Letters 121, No. 6, 2141-2142 (June 15, $1962)$

New uses of microfilm with electronic scanners, a progress report on FOSDIC III, M. L. Greenough, Proc. 8th Annual Meeting Natl. Microfilm Assoc., Wash. D.C., Apr. 2-4, 1959 , p. 278 (Annapolis, Md., 1959).

Susceptor elements for high temperature induction heating, S. Hasko and H. S. Parker, Am. Ceram. Soc. Bull. 41, No. 7, 467 (July 1962).

Relation of solar active regions at central meridian passage to ionospheric disturbance, C. S. Warwick and J. V. Lincoln,

AGARDograph Proc, Sixth AGARD Ionospheric Research Committee Meeting (Rome, Italy, May 15-18, 1961).

Radiolysis of ethane-1,1,1,-d $d_{3}$, L. J. Stief and P. Ausloos, J. Chem. Phys. 36, No. 11, 2904 (June 1, 1962)

Radiowave propagation during world war II, K. L. Norton, Proc. Re 50, No. 5, 698-704 May 1962)

Development directions to keep leather apace, J. R. Kanagy, Leather \& Shoes 142, 34-35 (Aug. 12, 1961).

Radio propagation quality in the North Atlantic area 1953 1960, M. E. Nason, AGARDograph Proc. 6th AGARD Ionospheric Research Committee Meeting (Rome, Italy, May 15-18, 1961)

Discussion of Feldman's and Sereda's Paper Characteristics of sorption and expansion isotherms of reactive limestone aggregate, C. M. Hunt, L. A. Tomes, R. G. Pike, and D. Hubbard, J. Am. Concrete Inst. 59, 815-818 (Mar. 1962).

The National Bureau of Standards Library, S. A. Jones, D. C. Libraries 32, 7-10 (Jan. 1961)

Systematic errors, W. J. Youden, Ordnance XLVI, No. 248, 299-301 (Sept.-Oct. 1961).

Heat of formation of the most stable form of metaboric acid, $\mathrm{HBO}_{2}(\mathrm{cI})$, M. V. Kilday and E. J. Prosen, J. Am. Chem. Soc. Commun. to Editor 82, 550 (1960).

The scientific contributions of William Weber Coblentz, E. K. Plyler, J. Appl. Spect. 16, No. 3, 73-77 (1962).

Absorption spectrum of $\mathrm{CF}_{2}$ trapped in an argon matrix A. M. Bass and D. E. Mann, J. Chem. Phys. 36, No. 12, 3501-3502 (June 15, 1962).

A test method for air-entrainment of standard Ottawa sand, M. R. DeFore and H. J. Corah, ASTM Bull. No. 248, 48-56 (TP162-166) (Sept. 1960).

The angular distribution of beta particles from oriented cerium-141 nuclei, D. D. Hoppes, Proc. Seventh Intern. Conf. Low Temperature Physics, University of Toronto, Canada, Aug. 1960, p. 186 (University of Toronto Press, Toronto, Canada, 1960).

Die radiometeorologie and ihre bedeutung fur die aus breitung der m-, dm- and $\mathrm{cm}$ - wallen auf grosse entfernungen, B. R. Bean, L. Fehlhaber, and J. Grosskopf, Nachr. Z (NTZ), pp. 9-16 (Jan. 1962).

The program at the National Bureau of Standards, L. M Branscomb, Book, Optical Spectroscopic Measurements of High Temperatures, ed. P. J. Dickerman, p. 235 (Univ. of Chicago Press, Chicago, Ill., 1961). 
Study of "valley problem" with a ray tracing program, K. Davies and A. K. Saha, Electron Density Profiles, pp. 162-166 (1962)

The extrapolation of the orthorhombic $N$-paraffin melting properties to very long chain lengths, M. G. Broadhurst, J. Chem. Phys. 36, No. 10, 2578 (Mav 15, 1962).

Oscillatory phenomena, A. H. Kahn (Proc. Conf. High Magnetic Field, Mass. Inst. Tech. Cambridge, Mass., Nov. 1-4, 1961), Book, High Magnetic Fields, pp. 480-488 (Mass. Inst. Tech. Press, Cambridge, Mass., and John Wiley \& Sons, Inc., New York, N.Y., 1962).

The information problem in government, S. N. Alexander, Proc. Engineering Information Symp. (Sponsored by the Engineers Joint Council), pp. 15-16 (Jan. 17, 1962).

Problems in the temperature calibration of an X-ray diffractometer furnace, F. A. Mauer and L. H. Bolz, (Proc. Tenth Annual Conf. Applications of X-ray Analysis, Denver, Colo., Aug. 7-9, 1961), Book, Advances in X-ray Analysis, p. 229 (Plenum Press, Inc., New York, N.Y., 1962).

The detection and study of solar cosmic rays by radio techniques, D. K. Bailey, (Intern. Conf. on Cosmic Rays and the Earth Storm), J. Phys. Soc. Japan 17, Suppl. A-1, Pt. I, 106-112 (1962).

Precision and accuracy-experiment design aspects, C. Eisenhart, Conf. on Applications of Statistical Methods in the Chemical Industry, Feb. 4, 1961, (Sponsored by Am. Soc. for Quality Control, Metropolitan Section, Seaton Hall University, South Orange, N.J.), p. 1 (1961).

Games associated with a renewal process, M. M. Siddiqui, Ann. Math. Stat. 33, 697-701 (June 1962).

Purification and vapor pressure of pure nitric oxide, E. E. Hughes, J. Chem. Phys. Letter to Editor 35, No. 4, 15311532 (Oct. 1961).

U]trasounds induce flaking of ceramics from metals, J. W. Pitts, Metal Progr. 82, No. 2, 114-115 (Aug. 1962).

Use of gas phase chromatography for rapid determination of carbonate at low levels, F. G. Carpenter, Anal. Chem. 34, 66 (Jan. 1962)

An experimental investigation of the scintillation of radio stars observed at frequencies of 223 and 456 megacycles per second from a location close to the auroral zone, C. G. Little, G. C. Reid, E. Stiltner, and R. P. Merritt, J. Geophys. Res. 6\%, No. 5, 1763-1784 (May 1962).

The radiative formation and destruction of negative ions, L. M. Branscomb, Proc. Fifth Intern. Conf. Ionization Phenomena in Gases, Munich, Germany, I, 1-18 (North Holland Publ. Co., Amsterdam, The Netherlands, 1961).

A computer for weather data acquisition, P. Meissner, J. A. Cunningham, and C. A. Kettering, Proc. Eastern Joint Computer Conf., Dec. 13-15, 1960, p. 57 (New York, N.Y., 1960).

Position titles of chemists, W. K. Wilson, Capital Chemist 10, 145 (May 1960).

Corrected calculations of sound absorption in non-associated liquids, R. E. Nettleton, J. Acoust. Soc. Am. 34, No. 3, 350 (Mar. 1962).

International comparisons of radioactivity standards, W. E. Perry and W. B. Mann, Proc. Ninth Intern. Congress on Radiology, Munich, Germany, July 1959, 23, VII-30. VII, 1338-1342 (Urban and Schwarzenberg, Munich, Germany, 1960).

Criteria for the reality of matrix eigenvalues, M. P. Drazin and E. V. Haynsworth, Z. Math. 78, 449-452 (Mar. 1962).

A rapid simple method of estimating the order of chemical reactions, J. H. Flynn, Chem. Eng. 69, No. 17, 137-140 (Aug. 20, 1962).

Paramagnetic resonance phenomena, H. E. Radford, Encyclopaedic Dictionary of Physics 5, 293 (Pergamon Press Inc., New York, N.Y., 1962).

Chilled-air-distribution in refrigerated traliers, P. R. Achenbach, Suppl. Bull. Intern. Inst. of Refrigeration, p. 9 (1961-1962).

Mass spectrum and appearance potentials of tetrafluorohydrazine, J. T. Herron and V. H. Dibeler, J. Chem. Phys. 33, No. 5, 1595-1596 (Nov. 1960).

A survey of polar cap absorption events (solar proton events) in the period 1952 through 1960 , D. K. Bailey and J. M. Harrington, (Intern. Conf. on Cosmic Rays and the Earth
Storm), J. Phys. Soc. Japan 17, Suppl. A-II, Pt. II, 334-337 (1962).

Isotope effect in an electric field and jump frequencies for diffusion in ionic crystals, J. R. Manning, J. Appl. Phys. 33, No. 7, 2145-2151 (July 1962).

Determination of isotope effects by "double labeling" oxidation of $d$-glucose with iodine, H. S. Isbell, L. T. Sniegoski, and H. L. Frush, Anal. Chem. 34, No. 8, 982-984 (July 1962)

Methods of nuclear orientation, E. Ambler, Book, Progress in Cryogenies, ed. K. Mendelssohn III, 235-280 (Heywood and Co., Ltd., London, England, 1960)

Molecular collision models and transition probabilities in liquids, R. E. Nettleton, J. Chem. Phys. 38, 2226-2227 (Apr. 1962).

Electronic development and production in the USSR, C. P. Marsden, Encylcopedia on Russia and the Soviet Union, pp. 158-160 (McGraw-Hill Book Co., Inc., New York, N.Y., 1961).

Microwave spectrum of trimethylarsine, D. R. Lide, Jr., Spectrochem. Acta 15, 473 (1959).

Lattice frequencies and rotational barriers for inorganic carbonates and nitrates, R. A. Schroeder, C. E. Weir, and E. R. Lippincott, J. Chem. Phys. 36, No. 10, 2803-2804 (May 1962).

Environmental characteristics of a small underground fallout shelter, P. R. Achenbach, F. J. J. Drapeau, and C. W. Phillips, ASHRAE J. 4, No. 1, 21 (Jan. 1962).

Chemically induced vibrational excitation: hydroxyl radical emission in the 1-3-micron region produced by the $\mathrm{H}+\mathrm{O}_{3}$ atomic flame, D. Garvin, H. P. Broida, and H. J. Kostkowski, J. Chem. Phys. 37, No. 1, 193 (July 1962).

Gas-phase radiolysis of propane, P. Ausloos and S. Lias, J. Chem. Phys. 36, No. 12, 3163-3170 (July 15, 1962).

The absolute simplest form in digital circuit design, R. S. Ledlev, Book, Digital Computers and Control Engineering, 835 pgs., (McGraw-Hill Book Co., Inc., New York, N.Y., 1960).

Infrared spectrum of dideuteroacetylene $\left(\mathrm{C}_{2} \mathrm{D}_{2}\right)$, E. D. Tidwell and E. K. Plyler, J. Opt. Soc. Am. 52, No. 6, 656-664 (June 1962).

The standards challenge, A. H. Scott, Insulation 8, No. 2, 48-50 (Feb. 1962)

A system for generating "pronounceable" names using a computer, A. L. Leiner and W. W. Youden, J. Assoc. Computing Mach 8, No. 1, 97-103 (Jan. 1961).

Using digital computers in the design and maintenance of new computers, A. L. Leiner, A. Weinberger, H. Loberman, and C. Coleman, IRE Trans. Electronic Computers EC-10, No. 4, 680-690 (Dec. 1961)

Surface preparation of solid metallic samples for X-ray spectrochemical analysis, R. E. Michaelis and B. A. Kilday, Book, Advances in X-ray Analysis 5, 405-411 (Plenum Press, Inc., New York, N.Y., 1962).

Infrared wavelength dependence of the total absorptivity of electroplated silver, D. Cline, J. Appl. Phys. 33, 2310-2311 (July 1962).

Simple stain gauge-based load controller, L. Mordfin and R. L. Bloss, Rev. Sci. Instr. 33, No. 7, 772-773 (July 1962).

Quantum-mechanical calculation of harmonic oscillator transition probabilities. II. Three-dimensional impulsive collisions, F. H. Mies and K. E. Shuler, J. Chem. Phys. 3y, No. 1, 177-181 (July 1, 1962)

Remote phase control of station WWV, R. F. Fey, J. B. Milton, and A. H. Morgan, Nature 193, No. 4820, 10631064 (Mar. 17, 1962).

Melting and contractility of feather keratin, L. Mandelkern, J. C. Halpin, and A. F. Diorio, J. Polymer Sci. Letter to Editor 60, No. 169, S31-S33 (July 1962)

Wave propagation around a curved boundary which contains an obstacle, J. R. Wait, Can. J. Phys. 40, 1010-1016 (Aug. 1962).

Duration and spacing of sferic pulses, R. F. Iinfield and C. A. Samson, Proc. IRE 50, 1841-1842 (Aug. 1962).

$\mathrm{VHF}$ and UHF signal characteristics observed on a long knife-edge, A. P. Barsis and R. S. Kirby, IRE Natl. Conv. Record, pp. 17-34 (1961).

Some observations on growing crystals of argon, L. H. Bolz, H. P. Broida, and H. S. Peiser, Acta Cryst. 15, No. 8, 810-812 (Aug. 1962). 
Methods and techniques of low and very low frequency monitoring at Boulder Laboratories, A. H. Morgan and D. H. Andrews, Consultative Committee for Definition of the Second Intern. Comm. on Weights and Measures, Apr. 11-12, 1961, pp. 1-10 (June 1961).

Physical measurement: Pilot of progress, A. V. Astin, Steel, p. 112 (July 23, 1962).

Vacuum photolysis of solid ethane at $77^{\circ} \mathrm{K}, \mathrm{M}$. D. Scheer, J. McNesby, and R. Klein, J. Chem. Phys. 36, No. 12, 3504-3505 (June 1962).

Geomagnetic and solar data, J. V. Lincoln, J. Geophys. Res. 6\%, No. 5, 2035-2038 (May 1962).

Supporting evidence for solar flare effects in the $F$ region of the ionosphere, R. W. Knecht and K. Davies, Nature 192, No. 4800, 348-350 (Oct. 28, 1961).

Dependence of interval between flare and associated sudden commencement storm on prestorm conditions, M. W. Haurwitz, J. Geophys. Res. Letter 67, 2979-2982 (July 1962)

The application of NMR in determination of the structure of cyclanols, I. The structures of cyclohexane-1,3-diols, H. Finegold and H. Kwart, J. Organic Chem. 27, 2361-2365 (1962)

Spectrophotofluorometric studies of degraded cotton cellulose, S. D. Toner and K. F. Plitt, Tappi 45, No. 8, 681-688 (Aug. 1962).

Algorithm and rapid binary division, R. S. Ledley and J. B. Wilson, IRE Trans. Electronic Computers EC-10, No. 4, 662-670 (Dec. 1961)

Opportunities in dental research, G. C. Paffenbarger, J. Am. Dental Assoc. 60, No. 3, 413-414 (Mar. 1960).

On the nature of equatorial slant sporadic $E, \mathrm{R}$. Cohen, K. L. Bowles and W. Calvert, J. Geophys. Res. 67, No. 3, 965-972 (Mar. 1962).

Elementary statistical design, W. J. Youden, Conf. on Applications of Statistical Methods in the Chemical Industry, Feb. 4, 1961 (Sponsored by Am. Soc. for Quality Control, Metropolitan Section, Seaton Hall University, South Orange, N.J.), p. 43 (1961).

Dielectric loss in "non-polar" polymers, A. J. Curtis, J. Chem. Phys. 36, No. 12, 3500 (June 15, 1962).

Mobilities of positive ions in argon, E. C. Beaty, Proc. Conf. Ionization Phenomena in Gases, Aug. 28-Sept. 1, 1961, Munich, Germany, p. 183 (North Holland Publ. Co., Amsterdam, The Netherlands, 1962)

Correction to "doppler studies of the ionosphere with vertical incidence," K. Davies, Proc. IRE 50, No. 6, 94 (June 1962).

Electron photo-detachment from ions and elastic collision cross sections for $\mathrm{O}, \mathrm{C}, \mathrm{Cl}$ and $\mathrm{F}, \mathrm{J}$. W. Cooper and J. B Martin, Phys. Rev. 126, No. 4, 1482 (May 15, 1962).

The following articles were presented before the 1961 Cryogenic Engineering Conference and published in the Book, Advances in Cryogenic Engineering $\boldsymbol{\gamma}$ (Plenum Press, Inc., New York, N.Y., 1962):

A cryostat for tensile tests in the temperature range $300^{\circ}$ to $4{ }^{\circ}$ K, R. P. Reed, Paper K-3, 448-454.

A method of measuring shear modulus from $-424^{\circ}$ to $70^{\circ} \mathrm{F}$, R. P. Mikesell and R. M. McClintock, Paper K-11, 509513.

An electrically controlled guarded flat plate calorimeter, D. Cline and R. H. Kropschot, Paper L-5, 534-538.

An experimental investigation of the individual boiling and condensing heat transfer coefficients for hydrogen, D. E. Drayer and K. D. Timmerhaus, Paper J-6, 401-412.

Dry gas operation of ball bearings at cryogenic temperatures, L. E. Scott, D. B. Chelton, and J. A. Brennan, Paper G-3, $273-276$.

Low temperature characteristics of some commercial thermocouples, R. L. Powell and L. P. Caywood, Jr., Paper L-2, $517-521$.

Martensitic transformation products and mechanical properties of austenitic stainless steels at low temperatures, C. J. Guntner and R. P. Reed, Paper K-9, 500-502.
On the bulk density of boiling liquid oxygen, R. W. Arnett, Paper F-4, 214-218.

Temperature dependence of magnetic losses, J. J. Gniewek and R. L. Powell, Paper H-1, 303-310.

Testing of ball bearings with five different separator materials at $9200 \mathrm{RPM}$ in liquid nitrogen, J. A. Brennan, W. A. Wilson, R. Radebaugh, and B. W. Birmingham, Paper G-2, $262-272$

The application and behavior of elastomers at cryogenic temperatures, R. F. Robbins, D. H. Weitzel, and R. N. Herring, Paper $\dot{\mathrm{H}}-6$, 343-352.

The application of gas-lubricated bearings to a minature helium expansion turbine, B. W. Birmingham, H. Sixsmith, and W. A. Wilson, Paper A-4, 30-42.

The efficiency of an ideal refrigerator, R. B. Jacobs, Paper L-11, 567-571.

The following papers were published in the Book:

Analytical Chemistry of Polymers, Parts II and III (Book), Ed. G. M. Kline (Vol. XII of High Polymers Series, Interscience Publ., New York, N.Y., 1962):

Part II. Analysis of molecular structure and chemical groups. 619 pages.

I. Molecular weights and sizes, S. G. Weissberg, S. Rothman, and M. Wales, pp. 1-77.

II. X-ray diffraction, A. S. Posner, pp. 79-108

III. Optical methods, A. F. Forziati, pp. 109-157.

IV. Differential thermal analysis, H. E. Kissinger and S. B. Newman, pp. 159-179.

V. Pyrolysis, L. A. Wall, pp. 181-248.

VI. Mass spectrometry, L. A. Wall, pp. 249-268.

VII. Ultraviolet spectrophotometry, M. Tyron and E. Horowitz, pp. 269-289.

VIII. Infrared spectrophotometry, M. Tryon and E. Horowitz, pp. 291-333.

IX. Fluorescence, A. F. Forziati, pp. 335-357.

X. Chromatography, J. M. Cassel, pp. 359-404

XI. Polarography, G. M. Brauer, pp. 405-485.

XII. Magnetic resonance spectroscopy, L. A. Wall and R. E. Florin, pp. 487-559.

Author index, subject index, pp. 561-619.

Part III. Identification procedures and chemical analysis 566 pages.

I. Systematic procedures, G. M. Brauer and E. Horowitz, pp. 1-140.

II. Color tests, G. M. Brauer and S. B. Newman, pp. $141-259$.

III. Microscopy, S. B. Newman, pp. 261-348.

IV. Radiochemical analysis, R. E. Florin and L. A. Wall, pp. 349-395.

V. End-group analysis, M. Hellmann and L. A. Wall, pp. $397-411$

General References, pp. 413-419.

Cumulative subject and author index, pp. 421-566.

Emission spectra of solids condensed at very low temperatures from the electrical discharge products of nitrogen and carbon monoxide or acetylene, S. L. N. G. Krishnamachari, R. W. Nicholls, and H. P. Broida, Proc. Indian Acad. Sci. LIV , 61-68 (1961)

Excitation of the red and green coronal lines, C. Pecker and R. N. Thomas, Ann. Astrophys. 25, 100-108 (Mar.-Apr. 1962).

Dependence of the ionospheric $F$ region on the solar cycle, J. W. Wright, Nature 194, No. 4827, 461-462 (May 1962). Boolean matrix equations in digital circuit design, R. S. Ledley IRE Trans. Electronic Computers EC-8, No. 2, 131-139 (June 1959).

*Publications for which a price is indicated are available from the Superintendent of Documents, U.S. Government Printing Office, Washington 25, D.C. (foreign postage one-fourth additional). Reprints from outside journals and the NBS Journal of Research may often be obtained directly from the authors. 